\title{
Acords fiscals de prestadors jueus forasters en el Liber secretariorum aliame judeorum Minorise (Manresa, 1343-1346)
}

\author{
Josep Xavier Muntané Santiveri* \\ Universitat de Barcelona
}

ACUERDOS FISCALES DE PRESTAMISTAS JUDÍOS FORASTEROS EN EL LIBER SECRETARIORUM ALIAME JUDEORUM MINORISE (MANRESA, 1343-1346).- El Liber secretariorum aliame judeorum Minorise es, de los dos únicos ejemplares de este género de liber iudeorum conservados en Cataluña, el más extenso. Contiene un registro de documentos en general relacionados con la fiscalidad de la aljama de Manresa, validados entre 1342 y 1353. Los secretarios de la comunidad aparecen en la mayoría de dichos documentos, especialmente en los acuerdos económicos pactados con judíos no residentes en Manresa pero con actividad crediticia en la ciudad (1343-1346). El artículo analiza las cláusulas de este tipo de contrato y edita críticamente esta documentación inusual.

Palabras Clave: Cataluña; siglo XIV; liber iudeorum; crédito; fiscalidad; secretarios de aljama.

Tax Agreements of Non-Resident Jewish Moneylenders in the Liber SeCretariorum aliame JUdEORUM MiNoRISE (MANRESA, 1343-1346).- The Liber secretariorum aliame iudaeorum Minorisa is, of the only two copies of this kind of liber iudeorum preserved in Catalonia, the most extensive. It registers documents generally related to taxation of the aljama of Manresa, validated between 1342 and 1353. The secretaries of the community appear in most of these documents, especially in tax agreements made with non-resident Jews in Manresa but with lending activity in the city (1343-1346). This article analyzes the clauses of this type of contract, and critically edits this unusual documentation.

Keywords: Catalonia; Fourteenth Century; liber iudeorum; Credit; Taxation; Secretaries of aljama.

\footnotetext{
*xavimuntane@hotmail.com
}

Copyright: (C) 2016 CSIC. This is an open-access article distributed under the terms of the Creative Commons Attribution (CC-by) Spain 3.0 License. 


\section{INTRODUCCIÓ}

El fons medieval de l'Arxiu Comarcal del Bages, a Manresa, des d'ara ACBG, compta amb una de les sèries de libri iudeorum més completes de Catalunya, junt amb les de Castelló d'Empúries, Vic i Besalú1. El primer d'aquests volums comença l'any $1294 \mathrm{i}$ el darrer acaba prop de cent anys després, el 1392. Si deixem de banda els mesos no coberts entre volum i volum, ja que no sempre la continuïtat temporal és tan exacta, els anys que queden fora dels períodes d'activitat notarial són escassos: 1314-1316 i 1332.

El llibre del qual extrec la documentació que estudio en aquest article data de mitjan segle XIV. A sobre de la tapa en pergamí que el protegeix s'hi va escriure fins a tres vegades, potser a manera d'exercici d'escrivent, el seu títol: Liber secretariorum aliame judeorum Minorise, des d'ara LS, amb una datació, afegida posteriorment, incorrecta: 1343-1453. En efecte, els anys dels documents recollits en aquest manual van de 1342 a 1353.

Pel títol ja es veu que és un llibre particular dins dels libri iudeorum conservats a Catalunya ${ }^{2}$. El seu contingut ho confirma. En aquest manu-

${ }^{1}$ I. LLOP, «Els Libri Iudeorum als arxius catalans», en Actes del III Congrés per a l'Estudi dels Jueus en Territoris de Llengua Catalana, 15-18 d'octubre de 2007. Barcelona-Perpinyà (en premsa). El total de libri iudeorum conservats en arxius catalans és, segons Llop, de 195 exemplars entre llibres i fragments de llibres. Les sèries més importants es troben a Castelló d'Empúries (91), Vic (28), Besalú (22) i Manresa (22). Els exemplars de Manresa estan distribuïts en dos arxius i tres fons diversos: dinou en l'ACBG (divuit en el fons de l'arxiu històric de protocols de Manresa i un en el fons de la cort del Veguer) i tres a l'arxiu de la Seu de Manresa (la seva datació, segons consta en catàleg, és dels anys 1230-1232, 1313-1317 i 1329, i en el cas del primer exemplar, catalogat com a 'llibre particular de jueus', precedeix en poc més de seixanta anys el liber ideorum més antic conservat a l'ACBG), M. Torras, B. Masats, R. Valdenebro i L. Virós, Catàleg dels protocols notarials de Manresa (Barcelona 1993), vol. 1, ps. 61 i 195-197; M. Torras, Inventari del fons del Veguer i del Batlle de Manresa (Manresa 1993) p. 31.

${ }^{2}$ Entre els libri iudeorum de Castelló d'Empúries n'hi ha un amb un títol similar: Liber secretariorum et comunis aljame iudeorum ville Castilionis (1346-1361), el qual, junt amb el de Manresa, són els únics exemplars del seu gènere a Catalunya, I. Llop, «Els Libri iudeorum» (en premsa); J. Fort, E. Serna i S. Soler, Catàleg dels Protocols del districte de Figueres (I) (Barcelona 2001) p. 136. En cap dels estudis publicats fins a la data present sobre l'aljama manresana s'estudia de manera específica aquest llibre singular, J. M. DE MAS, Memoria histórica de los judios en Manresa (Manresa 1836) 
al, validat per diversos notaris ${ }^{3}$, s'hi va registrar documentació relativa a la comunitat jueva de Manresa. De vegades els actors són un reduït nombre de jueus, els càrrecs dels quals, en cas de tenir-ne, no s'especifica, encara que en més d'un document hom intueix que aquest grup representava la resta de membres de la comunitat ${ }^{4}$. Unes altres vegades, la majoria, entre els actors dels documents hi figuren els secretaris de l'aljama manresana.

Tot i que a la resta de libri iudeorum catalans hi solen aparèixer també documents relatius a les comunitats, de vegades lligats a l'activitat dels seus responsables, cap d'ells es dedica a recopilar exclusivament aquesta mena de documentació comunitària, sinó que aquesta s'hi barreja amb la de particulars jueus que és, de fet, la dominant.

Malauradament, al LS de l'ACBG no hi ha pas tota la documentació generada per l'aljama al llarg d'aquells anys. Els 44 folis del llibre ${ }^{5}$ i els

[annex a Ensayos históricos sobre Manresa]; J. M. DE Mas, Ensayos históricos sobre Manresa (Manresa 1882) ps. 193-208; I. LoEB, «Notes sur l'histoire des juifs d'Espagne. Les juifs de Manresa», Revue des Etudes Juives 5 (1882) ps. 285-288; J. SARRET, Jueus a Manresa (Manresa 1917); J. JACOBS, An Inquiry into the Sources of the History of the Jews in Spain (London 1894) ps. 81 i 154-159 [E. TAMARo] i J. SARrET, «El testament d'un jueu. Segle XIV», Butlletí del Centre Excursionista de Bages 132 (1929) ps. 356-357; F. BAER, Die Juden im christlichen Spanien. Urkunden und Regesten. I: Aragonien und Navarra (Berlín 1929) ps. 309, 339, 381, 411, 687 i 689; M. C. MAÑÉ i G. EsCRIBÀ, Regesta of the Cartas Reales in the Archivo de la Corona de Aragón. Part I: 1066-1327 (Jerusalem 1993), doc. 55, 206, 366; M. C. MaÑÉ i G. EscribÀ, Regesta of the Cartas Reales in the Archivo de la Corona de Aragón. Part II: 1328-1493 (Jerusalem 1995), doc. 599, 730, 732, 736, 891, 1000, 1015, 1025, 1030, 1282; Y. T. Assis, The Golden Age of Aragonese Jewry. Community and Society in the Crown of Aragon, 1213-1327 (London - Portland, Or. 1997) ps. 43 i 184; J. X. MuntanÉ, «El testament i l'inventari d'Astruc Iossef, jueu prestamista de Manresa (1391), seguits d'un inventari i un testament menors», Iberia Judaica 5 (2013) ps. 101-133.

${ }^{3}$ Els notaris que validen els documents són Jaume d'Arters, Pere Nadal, Pere de Bellsolà, Francesc Roig, Pere de Gostemps, Bernat de Comes, Arnau de Torruella, Francesc Bisbals i Francesc de Gamiçans.

${ }^{4}$ En una ocasió, a l'inici d'un nomenament de procuradors s'escriu els noms del secretari i de sis jueus més però a continuació, s'indica que els jueus que s'havien reunit a la sinagoga del call (facientes aliamam) eren setze. El fet que en aquest cas s'hagués registrat el nom d'uns pocs assistents i no els de tots potser es devia a la funció que aquells tenien a l'aljama, LS, fs. 16r-17v (5/3/1346).

${ }^{5}$ Exactament, el LS té una extensió de 44 folis i aplega a més 5 fulls solts i 1 bifoli. 
130 documents registrats en ells ${ }^{6}$ són insuficients per poder encabir dotze anys de gestió. Una consulta detallada del seu contingut corrobora aquesta primera impressió.

L'activitat econòmica és la que aglutina el major nombre de documents. Quasi tota gira al voltant de les diverses gestions relatives al pagament de les contribucions al fisc reial ${ }^{7}$. Les àpoques de pagament atorgades per col·lectors reials d'impostos o pels seus procuradors es van succeint una al darrere de l'altra al llarg dels anys documentats ${ }^{8}$. A aquests pagaments fets al tresor reial ja sigui per particulars jueus o pels secretaris de l'aljama, s'hi han d'afegir els que la comunitat de Manresa havia d'efectuar a altres instàncies de poder, com la casa de Cardona", el col·lector dels terços de la cúria del batlle de Barcelona ${ }^{10}$ o l'infant Joan $^{11}$.

En els primers anys documentats al LS (1343/1345) es concentren les moratòries acordades entre el col·lector reial i diversos contribuents jueus

${ }^{6} \mathrm{El}$ nombre de documents que figuren en els 44 folis és pot classificar de la manera següent: 1342 (1 doc.), 1343 (25), 1344 (7), 1345 (16), 1346 (14), 1347 (8), 1348 (14), 1349 (9), 1350 (5), 1351 (9), 1352 (15) i 1353 (7).

${ }^{7}$ Més endavant ens referirem a les contribucions d'aquest tipus que figuren al LS. Aquí ens remetem als estudis sobre fiscalitat reial a les aljames catalanes que tot i tractar documentació prèvia al període del LS, tanmateix pertany a la primera meitat del segle XIv, de quan la comunitat de Manresa formava part de la col·lecta de Barcelona, P. Bertrán, «La fiscalidad extraordinaria de las aljamas de judíos de la corona de Aragón (1309-1317)», Sefarad 52:2 (1992) ps. 305-322; M. SÁNCHEZ, «La fiscalidad catalanoaragonesa y las aljmas de judíos en la época de Alfonso IV (13271336): los subsidios extraordinarios», Acta historica et archceologica medicevalia 31 (1982) ps. 91-141; M. SÁnchez, «Els jueus i el poder reial», L'Avenç 81 (1985) ps. 326-329; Y. T. Assis, Jewish Economy in the Medieval Crown of Aragon 1213-1327. Money and Power (Leiden 1997) ps. 160-173.

${ }^{8}$ ACBG, LS, fs. 5r (1343), 9r-v (1343), 9v (1343), 10r (1344), 11r-v (1344), 18v-19v (1346), 21v (1346), 21v-22r (1346), 22r (1346), 22v-23v (1346), 24r (1347), 26r-v (1348), 27r (1348), 27v (1349), 28r (1349), 28v (x2, 1349), 29r (x2, 1349), 31r (1350), 31r-v (1351), 31v-32v (1351), 33r (1351), 34v (1351), 36r (x2, 1352), 36v (1352), 37r (1352) i 44r (1353). Per a anys posteriors, F. BAER, Die Juden, ps. 380-381 (1354).

${ }^{9}$ ACBG, LS, fs. 28v (1349), 40v-41r (1352), 41r (1352), 43r (1353) i 44r (1353).

${ }^{10}$ ACBG, LS, f. 39r-v (1352).

${ }^{11}$ ACBG, LS, f. 44v (1353). 
de Manresa ${ }^{12}$. Dins d'aquest esforç per poder pagar al fisc reial cal enumerar també els deutes contrets per l'aljama amb particulars cristians ${ }^{13} \mathrm{i}$ jueus $^{14}$, el nomenament de procuradors per part de l'aljama o dels seus secretaris $^{15}$, i les avinences fetes entre diversos particulars i els representants de l'aljama quant a les quantitats amb què contribuirien al comú ${ }^{16}$. Les àpoques atorgades pels secretaris als contribuents que havien complert amb la part amb què havien estat taxats, testimonien l'efectivitat dels acords presos ${ }^{17}$.

El fet que els trasllats dels documents de la Cancelleria reial de Pere III que van ser copiats al LS tinguin a veure només amb el pagament de tributs i exaccions ${ }^{18}$, és un altre indici del pes que la fiscalitat reial té en aquest manual. Per això, els pocs documents econòmics del LS que semblen tenir un caràcter privat ${ }^{19} \mathrm{~s}^{\prime}$ han de contextualitzar segurament, en aquest marc fiscal.

Malgrat això, però, el LS no és un registre complet de l'activitat que es va dur a terme en aquest sentit. Per exemple, si sumem les àpoques del pagament fraccionat de determinats tributs, no s'arriba mai a completar la quantitat que calia satisfer, per tant en manquen.

${ }^{12}$ ACBG, LS, fs. 6r-v (1343), 6v-7v (x8, 1343), 8r (1343), 8v-9r (1343) i 14r-v (x11, 1345).

${ }^{13}$ ACBG, LS, fs. 10v-11r (1344), 11v (1344), 20v (1346), 26v-27r (x7, 1348) i 36v (1352).

${ }^{14}$ ACBG, LS, fs. 24v (1347), 25r (1348), 36r-v (1352) i 40r (1352).

${ }^{15}$ ACBG, LS, fs. 4v (1343), 5v (1343), 8v (1343), 10r-v (1344), 16r-17v (1346) i 22r-v (1346).

${ }^{16}$ ACBG, LS, fs. 1v-3r (1342), 4v-5r (1343), 5r (1343), 5v (1343), 15r-v (1345), 29v (1350), 35r-v (1351) i 37r-39r (1352).

${ }^{17}$ ACBG, LS, fs. 24v (1347), 25r (x2, 1347), 30v (1350), 33r (1351), 34v (x2, 1351), 35v (1352), 40v (1352), 41r (1352) i 43v (1353).

${ }^{18} \mathrm{~L}$ 'any indicat és el del trasllat: ACBG, LS, fs. 11v (1344), 12v-13r (1345), 28r (1349), 29v-30r (1350), 35r (1351) i 41v-42r (1353). Cal tenir en compte també, les còpies de documents reials reproduïdes en altres actes, sempre relacionades amb el pagament de tributs i exaccions.

${ }^{19}$ ACBG, LS, fs. 24r-v (1347, composició amical), 33v-34r (1351, cessió de drets), $35 \mathrm{v}$ (1352, àpoca del pagament d'un deute d'una jueva a un cristià), 36r-v (1352, comandadipòsit de diners entre jueus) i 40r (1352, comanda-dipòsit de diners entre jueus). 


\section{L'elecció de secretaris ${ }^{20}$, la seva activitat i el control de la mateixa ${ }^{21}$} és un altre dels aspectes que figuren al LS. Ara bé, si tenim en compte que la durada d'aquest càrrec era anual ${ }^{22} \mathrm{i}$ en algun cas, inferior a l'any ${ }^{23}$, al LS no s'hi van recollir totes les eleccions d'aquell període sinó només les dels anys 1345 i $1348^{24}$.

Prèviament ja ens hem referit al relleu que l'activitat fiscal duta a terme pels secretaris té en el $\mathrm{LS}^{25}$. A la seva vora, els documents que il·lustren altres aspectes de la seva gestió són gairebé anecdòtics. En aquest sentit, podem esmentar un document del 5 d'agost de 1353, relatiu al pagament del local que l'aljama havia llogat per tenir-hi la sinagoga, que fou efectuat pel secretari de torn. En canvi en dos documents anteriors, datats el 16 d'abril de 1348, relatius també al pagament del lloguer d'unes cambres que els jueus de Manresa utilitzaven com a sinagoga, cap dels jueus que hi intervenen ostenta un càrrec semblant ${ }^{26}$. És clar que, com a mínim entre

${ }^{20}$ ACBG, LS, fs. 13r-v (1345), 21r (1346) i 25r-v (1348).

${ }^{21} \mathrm{Al}$ LS no hi falten documents en què de manera expressa s'indica que es controlarà la gestió econòmica dels secretaris i la seva contribució personal als tributs i exaccions reials, ACBG, LS, 8r (1343), 13v-14r (1345).

${ }^{22}$ Tal com s'indica en la mateixa acta d'elecció: «huiusmodi mandatum duret et roboris obtineat firmitatem hinc ad unum annum primo venturum et non ultra», ACBG, LS, f. 13v (22/09/1345).

${ }^{23}$ El 23 de març de 1348 l'aljama escollí com a secretaris a Maimó Bonjuha, metge físic, i a Vidal Astruc Adret, per un mandat que havia d'acabar el dia de Nadal: «et voluit dicta aliama quod huiusmodi mandatum seu [...] duret et omnimodam obtineat roboris firmitatem hinc usque ad primo venturum festum Natalis Domini», ACBG, LS, f. 25v.

${ }^{24}$ El LS testimonia una concentració d'aquest càrrec en una mateixa família: Baró Jucef ho fou els anys 1343, 1345, 1346 i 1347; el seu germà Astruc Jucef, l'any 1345; un altre germà, Vidal Jucef, l'any 1348, i Bonanasc Alfaquim, gendre d'Astruc Jucef, figura com a secretari els anys 1350 i 1353.

${ }^{25} \mathrm{Hi}$ ha ocasions en què els secretaris reben els diners dels contribuents de la comunitat o de creditors amb qui s'han endeutat en nom de l'aljama, i amb ells paguen als $\mathrm{col} \cdot$ lectors reials les quantitats degudes. Altres vegades, els secretaris reben la promesa dels contribuents conforme aquells pagaran les quantitats que els pertoquen per taxació. No manquen les ocasions en què nomenen procuradors perquè els representin en qüestions fiscals. De manera puntual, tanquen diversos tipus de tractes amb jueus de la comunitat o forasters amb què es regula les seves contribucions durant períodes de temps determinats, per tal de sufragar les despeses comunitàries i el fisc reial.

${ }^{26}$ ACBG, LS, f. 26r. De manera semblant, en un document relatiu a l'adquisició d'un tros de terra per part de l'aljama de Manresa per fer-hi un fossar («ad opus 
aquestes dues dates, el pagament d'aquest lloguer es va realitzar periòdicament però, tret dels casos esmentats, el LS tampoc ho recull ${ }^{27}$.

D'altra banda, encara que al LS hi ha referències explícites a documentació interna hebraica i utilitza mots hebreus transcrits en català per referir-se a determinats elements, la llengua del LS és el llatín ${ }^{28}$ :

faciendis cautionem et securitatem literis ebraycis ut moris est per judeos fieri scriptam, vallatam cum alatme et nitduy et sauha sive iuramento per ipsum in manibus judeorum dicte aliame prestando ${ }^{29}$.

Així doncs, hi ha també una documentació comunitària produïda per la pròpia aljama, en hebreu o en aljamia ${ }^{30}$, que el LS ha deixat de banda.

cuiusdam siminteri in quo ciminterio ipse algame posint sepelire cadavera eidem judeis qui deseserint», f. 27v), de finals de 1348, el jueu responsable del pagament hi apareix qualificat com a secretari encara que després es ratllà la referència al càrrec i hom s'hi referí només com a jueu de Manresa.

${ }^{27}$ La localització de la sinagoga que figura en un document de 1348 és la següent: «in quadam domo vocata sinoga dicte aliame que est satis prope platheam dicte civitatis» (f. 25r). Coincideix amb la que consta en un document de 1343: «in quadam domo vocata sinoga aliame judeorum Minorise que est satis prope platheam eiusdem» (f. 10r). Per tant l'immoble era el mateix i podem ampliar a aquests anys previs a 1348 el pagament d'un lloguer que tampoc no consta al LS. Sobre altres pagaments del lloguer de la sinagoga, J. X. Muntané, «El testament i l'inventari d'Astruc Iossef», p. 109 nota 51. Encara que l'indret de referència era la plaça de Manresa, la sinagoga dels jueus de la ciutat estava situada dins del call: «in domo vocata sinoga que est in callo judaico Minorise, f. 13r (1345); in sinagoga callis judayci Minorise», f. 16r (1346).

${ }^{28}$ La flexió dels antropònims jueus en llatí al LS té una clara tendència, quan combina el nom del fill amb el del pare, a declinar el segon terme en genitiu. És una manera d'adaptar a la llengua llatina la relació de filiació que en hebreu/arameu s'expressa amb בן/בר els termes, mots que no es tradueixen mai en llatí. Hi ha exemples del que diem en els documents transcrits al final del article.

${ }^{29}$ ACBG, LS, f. 10v (1344).

${ }^{30}$ Dins dels territoris de domini lingüístic català trobem exemples de documentació jueva intracomunitària en què la llengua emprada és l'hebreu, amb mots catalans intercalats, i casos en què la llengua dominant és la catalana escrita amb caràcters hebreus, veg. respectivament M. Pujol, «Dues tabes hebraiques de l'aljama de Castelló d'Empúries», Calls 4 (1990) ps. 7-52; A. Duran, «Documents aljamiats de jueus catalans», Butlletí de la Biblioteca de Catalunya 5 (1918-1919) ps. 130-148: 140-148 (ordinacions de clavaria de Cervera, 1455). A Girona els secretaris tenien l'obligació de registrar els acords (anomenats 'scamoç' de l'hebreu הסכמות) presos en les reunions del consell, en un llibre específic, J. RIERA, Els jueus de Girona i la seva organització: segles 
No sabem si aquest llibre fou l'únic del seu gènere que hi va haver a Manresa o si, pel contrari, és l'únic exemplar que ha perviscut d'una sèrie de llibres similars. L'any del primer document (1342) ens remet al període immediatament posterior a la dissolució de la gran col-lecta de l'aljama de Barcelona, que va tenir lloc el 5 d'agost de $1341^{31}$, de la qual els jueus de Manresa n'havien format part. La comunitat de Manresa junt amb les comunitats de les altres ciutats que havien depès de Barcelona (Cervera, Montblanc, Tarragona i Vilafranca), van haver d'adaptar les estructures administratives i jurídiques existents a les que feien falta per poder funcionar com una comunitat per se. A Tarragona, per exemple, es té notícia de l'elecció de secretaris propis l'any $1343^{32}$.

És probable, doncs, que es pugui adscriure a aquesta nova etapa històrica la iniciativa d'aplegar en un llibre específic una part de l'activitat dels secretaris de la comunitat manresana.

\section{DOCUMENTACió FISCAL RELATIVA A JUEUS FORASTERS}

Una lectura del LS ofereix un seguit de dades interessants de cara a reconstruir, encara que només sigui parcialment, la contribució de l'aljama de Manresa a la fiscalitat reial durant el període comprès en el manual. Fins l'any 1341 l'aljama havia tributat amb la col·lecta de Barcelona i la seva participació es troba diluïda en les quantitats que en la documentació

XII-XV (Girona 2012), doc. 50 [22/12/1386] ps. 270-271. El més probable doncs, és que també a Manresa es registrés una part de l'activitat oficial de la comunitat o bé en hebreu o bé en aljamia hebraicocatalana.

${ }^{31}$ J. RIERA, Els poders públics $i$ les sinagogues. Segles XIII-XV (Girona 2006) p. 56. La divisió de la col-lecta de Barcelona provocà l'aparició de diverses qüestions que enfrontaren l'aljama de la Ciutat Comtal amb les de Manresa, Cervera, Vilafranca del Penedès i Montblanc, M. C. MaÑÉ; G. EscribÀ, Regesta of the Cartas Reales. Part II: 1328-1493, doc. 1000 (29/9/1342). En alguns documents del LS es fa referència a l'antiga pertinença de l'aljama de Manresa a la col-lecta de Barcelona, ACBG, LS, fs. $12 \mathrm{v}-13 \mathrm{r}$ (1345) i 14v (1345). L'any 1342 el rei separà també l'aljama de Besalú de la col·lecta de Girona.

32 J. Morelló, «En torno a la presión fiscal sobre las aljamas de judíos de Tarragona», Sefarad 71:2 (2011) ps. 293-348: 309. El Liber secretariorum et comunis aljame iudeorum ville Castilionis de Castelló d'Empúries comença també en aquesta mateixa dècada: l'any 1346. 
oficial s'adscriuen només a la comunitat que era el cap d'aquella collecta, Barcelona. Amb la dissolució de la col-lecta, l'aljama de Manresa adquirí un rang diferent i es convertí en un subjecte fiscal tal com fins llavors ho havia estat la comunitat de la Ciutat Comtal.

Les referències a pagaments de subsidis ordinaris i extraordinaris són abundants i entre les quantitats que l'aljama de Manresa hagué de satisfer al fisc reial n'hi ha de considerables: una assignació de 2.000 sous per a la reina Maria ${ }^{33}$; un subsidi extraordinari de $1343 \mathrm{amb}$ motiu de les accions bèl-liques empreses contra Jaume III de Mallorca al Rosselló i la Cerdanya, de 6.500 sous, apareix en nombrosos documents ${ }^{34}$; una bestreta de 3.000 sous del subsidi ordinari de l'any $1344^{35}$; un subsidi ordinari de 7.000 sous, a pagar en dos terminis els mesos de maig i setembre de $1345^{36}$; l'ordre reial de repartir entre l'aljama de Barcelona i les que havien format part de la seva col-lecta 4.000 sous, que havia de percebre Joan Porta, ciutadà de Barcelona ${ }^{37}$; en les dues ocasions en què apareixen desglossades les assignacions locals de 200 lliures que s'havien de recol·lectar entre diverses aljames catalanes, la contribució de Manresa és similar: 12 lliures, 7 sous i 6 diners, l'any 1346, i 25 lliures pels anys 1348 i 1349 junts $^{38}$; un subsidi ordinari de 2.000 sous, a pagar en dos terminis els mesos de maig i setembre de $1348^{39}$; un subsidi ordinari de 3.000 sous, a pagar en dos terminis els mesos de maig i setembre de $1351^{40}$.

La pressió exercida per la tresoreria reial sobre els jueus de Manresa fou notable. Com a consequiència de la mateixa, la comunitat s'endeutà més d'una vegada ja que no disposava dels diners que se li exigia ${ }^{41}$. De

${ }^{33}$ ACBG, LS, fs. 6r (17/7/1343) i 6r-v (2/10/1343).

${ }^{34}$ ACBG, LS, fs. 6v-7r (14/11/1343), 8r (9/12/1343), 8v-9r (9/12/1343), 9r-v (9-24/12/1343), 10r (15/1/1344) i 11r-v (10/7/1344).

${ }^{35}$ ACBG, LS, f. 12r (25/3/1344).

${ }^{36}$ ACBG, LS, fs. 21v (15/11/1346) i 21v-22r (17/11/1346).

${ }^{37}$ ACBG, LS, fs. $12 \mathrm{v}-13 \mathrm{r}$ (12/9/1345) i 14v (setembre-desembre, 1345).

${ }^{38}$ ACBG, LS, fs. 23r (21/12/1346) i 29v-30r (28/10/1350).

${ }^{39}$ ACBG, LS, f. 28r (octubre-novembre, 1349)

${ }^{40}$ ACBG, LS, f. 35r (13/1/1351).

${ }^{41}$ Entre els poders donats legalment per l'aljama a Rovén Salomó s'indica «quod SEFARAD, vol. 76:2, julio-diciembre 2016, págs. 251-288. ISSN: 0037-0894. doi: 10.3989/sefarad.016.009 
fet, les dates que consten en les àpoques de pagament d'alguns subsidis mostren que els terminis previstos en les ordinacions reials (maig i setembre) no sempre es van complir. De manera semblant, la negociació de nous termes de pagament entre el col-lector reial i diversos particulars de la comunitat jueva de Manresa, són un altre indici de les dificultats experimentades per aquests contribuents a l'hora de complir amb els seves obligacions fiscals ${ }^{42}$. En un cas fins i tot, es deixa constància de l'empresonament sofert per diversos membres de l'aljama ${ }^{43}$.

A més a més del funcionament de l'aljama en relació a les contribucions reials, el LS aporta altres dades relatives a despeses comunitàries com ara les derivades del lloguer del local que feia les funcions de sinagoga ${ }^{44}$,

vigore et auctoritate huius procurationis et sindicatus posit mutuo recipere pro eis et eorum nomine, tam a christianis videlicet quam judeis etiam sub usuris, viginti libras barchinonenses quas debeat et teneatur tradere et exsolvere illustrissime domine Marie, Dei gratie regine Aragonum, seu eius thesaurario ex eo quod eidem excellentissime domine regine restant ad solvendum seu tradendum de illis duobus mille solidis quos in mense madii proximo preterito eidem excellentissime domine regine ex assignatione seu ordinatione regia solvere et tradere tenentur», ACBG, LS, f. 6r (17/7/1343). Així mateix, els 2.740 sous que Berenguer Amargós i Bernat Valls, ciutadans de Manresa, van deixar en comanda a Astruc Jucef, fill del difunt Jucef Baró, David de Ripoll, Vidal Astruc Adret, Rovén Salomó, Jucef Cofén i Abamari Salomó, jueus de Manresa, van ser «missi et converssi [...] in negotiis aliame dicte civitatis», i els dits jueus es van comprometre a tornar-los en funció de la part proporcional que a ells i altres jueus els pertocava «contribuere in talliis et exactionibus per nos deinde fiendis et solvendis», ACBG, LS, fs. $10 \mathrm{v}-11 \mathrm{r}(2 / 7 / 1344)$.

${ }^{42}$ ACBG, LS, fs. 6r-v (1343), 6v-7v (x8, 1343), 8r (1343) i 8v-9r (1343). Algunes d'aquestes moratòries precedeixen en pocs dies a l'ordre que el rei donà als seus oficials i recaptadors de no obligar les aljames a pagar el que encara devien de tributs i subsidis, M. C. Mañé; G. EscribÀ, Regesta of the Cartas Reales. Part II: 1328-1493, doc. 1030 (17/11/1343). Aquell mateix any el rei ja havia exonerat els jueus de Manresa de pagar les penes de terç dels deutes que tenien contrets amb aquesta clàusula, per tal que poguessin satisfer les contribucions reials, M. C. MAÑÉ; G. EscriBÀ, Regesta of the Cartas Reales. Part II: 1328-1493, doc. 1015 (19/3/1343).

43 «Solvistis et tradidistis michi numerando vi et districtu curie, eo quare vos et quosdam judeos dicte aliame captos sub custodia detinebam, predictas duodecim libras septem solidos et sex denarios iuxta predicta litteram regiam vos in predictis solvere et contribuere contingentes», ACBG, LS, f. 22r (17-21/11/1346). Sobre aquest tipus de violència exercida sobre aljames o contribuents insolvents, Y. T. Assis, Jewish Economy, ps. 233-235.

$$
{ }^{44} \text { Veg. nota } 27 .
$$


les dels banys i de l'almoina ${ }^{45}$, i les de la celebració de la Pasqua jueva ${ }^{46}$. Són unes dades que permeten apropar el funcionament intern de la comunitat jueva de Manresa amb el de la resta de comunitats del seu temps ${ }^{47}$.

La documentació que estudiem en aquest article és tan sols una mínima part dels documents continguts al LS. Tot i això, el seu interès rau en el fet que es tracta d'una tipologia documental inèdita fins ara. Tal com tindrem l'oportunitat de veure a continuació, els documents presentats (apèndix doc. 1a, 1b, 1c, 2, 4, 5, 6) s'apropen als contractes ja coneguts de veïnatge però no s'hi identifiquen, ja que en cap moment s'afirma que tal jueu s'incardinarà a l'aljama de Manresa ni tampoc s'estipulen les condicions per a l'establiment d'un nou veít8 . La seva finalitat és una altra.

45 «In predictis autem nolo intelligi aut modo aliquo comprehendi missiones aut sumptus balneorum judeorum dicte aliame et helemosine eiusdem immo habeam et tenear solvere partem me in ipsis balneorum et helemosine dicte aliame sumptibus solvere contingentem per dictum tempus predictis non obstantibus ullomodo habeat autem promissionem et cetera [...] exceptis dum taxat dictis missionibus occasione dictorum balneorum judeorum et helemosine dicte aljame fiendis», ACBG, LS, f. 15r-v (13/12/1345).

${ }^{46}$ Veg. apèndix doc. 1a, 1b, 3. En cap moment s'especifica la natura de les despeses associades a les festivitats de Pasqua. En un document de 1326, Jaume II concedí a l'aljama de Manresa la facultat de coure els pans àzims a les seves cases en comptes de fer-ho als forns cristians, però no per això els eximí de pagar als propietaris o als qui percebien les rendes dels forns de la ciutat la part corresponent als dies de Pasqua: «Nos Jacobus et cetera, ut vos judei aljame civitatis Minorise panes non fermentatos seu azimos quibus in festo Pasche juxta legem vestram uti habetis possitis in domibus vestris decoquere seu decoqui facere vobis tamen solventibus dominis furnorum dicte civitatis seu emptoribus reddituum eorum jura que solvere haberitis si in furnis ipsis panes decoqui faceretis predictos», ACA, Canc., reg. 228, f. 45r (9/3/1326), J. RÉGné, History of the Jews in Aragon. Regesta and Documents 1213-1327 (Jerusalem 1978), doc. 3372.

${ }^{47}$ Y. T. Assis, The Golden Age, ps. 210-223 i 242-249; J. RIERA, Els poders públics, ps. 174-209.

${ }^{48} \mathrm{Al}$ mateix LS hi ha contractes de veïnatge: n'hem transcrit un a l'apèndix (doc. 3) i encara n'hi ha un altre d'un tal Salomó Vidal Sescaleta, jueu de Cardona, als fs. 37v-39r (3/9/1352). Les semblances amb contractes del mateix tipus estesos en altres llocs són interessants, com el d'Astruc Malet, jueu també de Cardona, recollit a M. GraelLs, «Documents de la vida quotidiana dels jueus de Cervera (1352-1353)», Miscel·lània Cerverina 11 (1997) ps. 183-198, doc. 3 (17/8/1352). La negociació que precedia a l'establiment d'un nou veí també la trobem documentada entre el govern municipal de Tàrrega, d'una banda, i jueus de Santa Coloma de Queralt i Montsó, de l'altra, J. X. Muntané, Fonts per a l'estudi de l'aljama jueva de Tàrrega. Documents i regesta (Barcelona 2006), doc. 266-267 (1366, Sta. Coloma de Queralt) i 361 (1446, Montsó). 
En aquests contractes els secretaris de l'aljama de Manresa negocien amb jueus forasters la suma que els hauran d'abonar per participar en el mercat del crèdit de la ciutat. Es tracta, en principi, de quantitats moderades per a ambdues parts: la taxa que els creditors jueus forasters havien de pagar era l' $1 \%$ del capital invertit sempre que no excedís dels 1.500 sous. En cas contrari, el gravamen es disparava al $12 \%$.

Aquests documents, doncs, la intenció dels quals sembla que sigui atreure capital jueu foraster a la ciutat per tal d'engrossir la recaptació de l'aljama, s'emmarquen dins del context econòmic presentat prèviament i de les gestions dutes a terme pels responsables de la comunitat per finançar les despeses i les obligacions fiscals de l'aljama.

\section{Nomenclatura I NATURALESA DELS DOCUMENTS}

En un d'aquests contractes, concretament en el segon document del contracte de Maimó Samuel (doc. 5), es qualifica aquest tipus de documentació de dues maneres. En un primer moment hom s'hi refereix emprant dos termes llatins, compositio et transactio, que remeten a la idea d'un acord estipulat entre dues o més persones en què l'arranjament final és el resultat de determinades concessions, en aquest cas, de caire econòmic i contributiu. Més endavant es pot llegir l'aclariment següent: «in instrumento dicte compositionis et transactionis [...] quod inter judeos sive ebrayce vocatur passara». El mot hebreu que l'escrivà llatí va transcriure d'oïda era פשרה (peixarà): 'acord', 'compromís', 'pacte'.

És significatiu que en la taba hebraica d'una compravenda de la imposició dels deutes de Castelló d'Empúries (1392), reaparegui aquest mateix tipus documental i que ho faci, precisament, en una clàusula en què s'estipula sobre exempcions fiscals, en aquell cas entre els secretaris de l'aljama i els jueus nouvinguts. Diu el text: ובעלי הבאה יפרעו כפי פשרתם

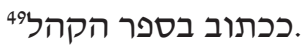

\footnotetext{
49 «Els nouvinguts pagaran segons la composició que hom hagi establert amb ells i estigui escrita al llibre de la comunitat», M. PuJoL, «Dues tabes hebraiques», art. XXI, p. 27 (català), p. 40 (hebreu).
} 
Estem per tant, doncs, davant d'un tipus d'acord de naturalesa econòmica molt més usual del que la seva presència en les fonts notarials llatines ens podria fer pensar. El fet que les parts participants fossin ambdues jueves i que el seu espai d'acció estigués restringit a l'àmbit intern de la fiscalitat comunitària explicarien aquesta escassetat de testimonis documentals. Així mateix, la pràctica estesa entre les aljames de guardar la documentació comunitària dins del recinte sinagogal ${ }^{50}$ seria una altra raó per la qual aquest tipus de document no abunda als arxius cristians ${ }^{51}$.

A això s'hi ha d'afegir també el fet de l'oralitat, exemplificat aquí en el document complementari (doc. 5) que Maimó Samuel va demanar que fos afegit a la seva פשרה (doc. 4). En ell hi consten unes condicions que no apareixen en el document previ però que, segons Maimó Samuel, havien estat convingudes de paraula entre ell i el secretari de l'aljama de Manresa: «acto cum et in pactum deducto verborum inter me et vos». Talment com si una part de la negociació fos oral i no escrita, cosa que devia neguitejar a Maimó Samuel. Tot i que és difícil poder establir la frequiència o l'abast d'aquests pactes orals, la seva existència fa encara més gran l'escletxa per la qual aquest tipus d'acords es perden en el temps.

\section{ACTORS}

Un o dos jueus de Manresa, en tant que secretaris, figuren sempre entre els actors d'aquests documents i constitueixen una de les parts contractants. El topònim Minorise que segueix invariablement a la denominació judeus/judei reforça, en aquest cas, el contrast que hi ha amb els actors de

${ }^{50}$ A la taba de Castelló d'Empúries aquesta prohibició es formula al final del plec de condicions: «Els compradors no podran treure el llibre de les declaracions fora del recinte de la sinagoga (חוץ מעזרת בית הכנסת) [...] estaran obligats a dipositar el llibre i l'enquesta a l'arca de la comunitat (בתיבת הקהל) בתז), , M. Pujol, «Dues tabes hebraiques», art. XXX, p. 29 (català), p. 41 (hebreu); J. RIERA, Els poders públics, ps. 206-207.

${ }^{51}$ Una de les excepcions més notables és l'Arxiu Històric de Girona, E. Feliu, «Llibre de comptes de Jucef Zabara, col·lector del clavari de la comunitat jueva de Girona (1443)», Tamid 5 (2004-2005) ps. 87-138; M. PeranI, «The "Gerona Genizah": An Overview and a Rediscovered Ketubah of 1377», Hispania Judaica Bulletin 7 (2010) ps. 137-173; E. VALLS, «L'impost de la renda de l'any 1427 (sobre els guanys de 1426) o l'egualtat dels guanyatges de la comunitat jueva de Girona», Materia Giudaica 17-18 (2012-2013) ps. 263-277. 
l'altra banda, identificats només com a jueus o bé com a jueus d'un altre lloc. Tant en un cas com en l'altre es tracta sempre de jueus forasters, de jueus que no són de Manresa (de Jucef Vidal i de Salomó Vidal es diu que habitaven a Vic) o no hi viuen (de Benvenist Rossell, Maimó Samuel i Bellsom Escapat només s'indica la seva condició legal de jueu ${ }^{52}$, sense complement topogràfic) ${ }^{53}$.

Una de les característiques d'aquests acords és que la residència a Manresa no figura entre els requisits obligatoris. El cas de Jucef Vidal, jueu de Vic, és un dels més clars en aquest sentit. En un full solt, conservat entremig dels folis inicials del LS i que es correspon amb l'esborrany de l'acte que després es va registrar en aquest manual, s'indica expressament que Jucef Vidal havia de traslladar el seu domicili a Manresa durant el temps que durés l'acord:

hinc ad festum sancti Michaelis septembris transtulero domicilium meum in civitate Minorise et ab ipso festo sancti Michaelis ad duos annos continue primo venturos et completos tenebo et fovebo domicilium meum in civitate Minorise (doc. 1c).

Aquesta clàusula, en canvi, no apareix en la redacció parcial del document (doc. 1b) ni tampoc en la definitiva (doc. 1a). El més probable és que Jucef Vidal no s'incardinés a l'aljama de Manresa, sinó que durant aquells anys continués residint a Vic. I si en algun moment ho va fer, el cert és que en la nota de cancel-lació de l'acord, inserida el 6 de maig de 1345 (doc. 1a nota 8), no s'indica pas que aquest jueu fos de Manresa a diferència del secretari, del qual sí que es deixa constància de la seva pertinença a aquesta ciutat ${ }^{54}$.

${ }^{52}$ Sobre aquesta designació, C. Denjean i J. Sibon, «Citoyenneté et fait minoritaire dans la ville médiévale. Étude comparée des juifs de Marseille, de Catalogne et de Majorque», Histoire urbaine 32 (2011) ps. 73-100: 87.

${ }^{53}$ D'altra banda, la qualificació dels secretaris com a jueus de Manresa sembla gairebé redundant si tenim present que una de les condicions per poder aspirar al càrrec de secretari era la residència en el lloc on s'exerciria aquesta funció, Y. T. Assis, The Golden Age, ps. 91-92; J. RIERA, Els jueus de Girona, doc. 50 (22/12/1386), p. 268.

${ }^{54}$ En contrast amb això, en una àpoca atorgada per Bonanasc Alfaquim, secretari de Manresa, a Salomó Vidal Sescaleta, un any després del seu contracte de veïnatge, ja no se l'identifica com a jueu de Cardona sinó com a jueu de Manresa, ACBG, LS, f. 43v (agost-setembre de 1353). 
Les condicions acordades per a Salamó Vidal, jueu de Vic, i per al seu gendre Benvenist Rossell (doc. 2), el contracte dels quals fou signat el mateix dia que el de Jucef Vidal i fet a semblança seva (fiat ut supra), no devien diferir en aquest punt ja que no s'indica el contrari.

El cas de Maimó Samuel, en canvi, no deixa cap dubte sobre aquest assumpte (doc. 4-5). En el document complementari annexat al primer acord -esmentat prèviament- s'indica específicament que el pacte acordat entre les parts perquè aquest jueu pogués negociar a Manresa no implicava, de fet, que hi residís: cum ego ibidem non foveam domicilium meum (doc. 5). De fet si durant el temps de vigència de l'acord, Maimó Samuel es traslladava a Manresa, això repercutia amb un enduriment de les condicions econòmiques estipulades prèviament.

El contracte de Bellsom Escapat (doc. 6) és similar al de Maimó Samuel en el sentit que una hipotètica domiciliació a Manresa implicava també una major pressió contributiva:

in casu tamen quo ego meum domicilium teneam seu foveam infra dictum tempus in dicta civitate prout domicilium est foveri et teneri assuetum dabo et solvam vobis ultra predicta per dictum tempus quinquaginta solidos.

De tota manera, tant si s'hi instal-lava com si no, mentre pagués les quantitats convingudes en els terminis fixats podia gaudir de les immunitats i privilegis de l'aljama de Manresa «sicut aliquem alium singularem dicte aliame».

\section{DURADA DELS ACORDS}

Cadascun d'aquests acords té una durada temporal limitada. Jucef Vidal (doc. 1) i Salomó Vidal (doc. 2) en van signar un per un temps de 2 anys, 7 mesos i 3 setmanes. No tenim una xifra rodona perquè en el seu cas es va començar a comptar a partir de la data del contracte ( 22 de gener) però no es va prendre aquella data com a punt de referència per comptar anys sencers, sinó que es va escollir una festa cristiana posterior (sant Miquel, 29 de setembre). En el cas de Jucef Vidal sabem que es rescindí l'acord uns quatre mesos abans de la data final prevista. 
La resta de pactes es van fer per una durada de 5 anys. En el de Maimó Samuel (doc. 4-5) es començà a comptar a partir de la data del contracte (30 de gener) i, en el de Bellsom Escapat (doc. 6), a partir d'una festivitat religiosa cristiana que s'esqueia a la fi del mes en què es va firmar el contracte (sant Joan Baptista, 24 de juny).

Quan s'indiquen els terminis de pagaments (doc. 4-6), es prenen com a referència diades remarcables del calendari cristià, no del jueu, tot $i$ tractar-se de documentació interna de l'aljama. En tots els casos les dates són les mateixes: Nadal i sant Joan Baptista. A Manresa, com també passa en la documentació produïda en les notaries d'altres municipis del bisbat de Vic, el sistema adoptat per al còmput dels anys no era el de l'Encarnació (25 de març) sinó el de la Nativitat ( 25 de desembre) ${ }^{55}$. Llavors, els terminis esmentats, que distribuïen els pagaments cada sis mesos, en situaven un a l'inici de l'any, i l'altre, a la meitat.

\section{Obligacions Fiscals}

Durant el transcurs d'aquests períodes de 3 o 5 anys el jueu foraster es convertia en subjecte fiscal de l'aljama manresana amb una quantitat contributiva determinada.

El motiu pel qual havia de contribuir amb l'aljama de Manresa tot i no residir-hi, eren els negocis crediticis que tenia en aquella ciutat. Així ho confirmen els secretaris a Jucef Vidal: «ratione peccunie cum qua negotiabimini in civitate Minorise et eius circumvicinio per totum dictum tempus» (doc. 1). O té cura de detallar-ho Maimó Samuel:

quod predictam peccunie quantitatem dictorum XV solidorum dem et tradam vobis dicto secretario et successoribus vestris in dicto officio vestro secretarie annuatim per dictum tempus, pro et ratione illarum peccunie quantitatum mearum cum quibus negotiabor in dicta civitate Minorise (doc. 4).

${ }^{55}$ L. Cases i I. Ollich, Catàleg dels arxius notarials de Vic (Barcelona 1986) p. 28; M. ToRras et alii, Catàleg dels protocols notarials de Manresa, vol. 1, p. 51; R. GinEBRA, «Un cas de dissidència cronogràfica: còmput cronològic a Vic i al bisbat de Vic, segles XII-XIV», Acta historica et archaeologica mediaevalia 20-21 (1999) ps. 561-590. 
Amb Jucef Vidal es pactà, primer, un impost vinculat als tributs que l'aljama havia de satisfer al fisc reial: per cada tribut (anual) de 1.700 sous Jucef Vidal es comprometia a pagar 15 sous. Cosa que es traduïa en una participació del 0,8\%. Ultra això, havia de contribuir amb les despeses anuals de l'aljama («in omnibus et singulis sumptibus et missionibus»), i s'establia que ho fes de manera proporcional en funció dels 15 sous amb què s'havia fixat la seva assignació tributària. De tota manera, hi ha un parell de conceptes amb els quals acceptà de contribuir no ja en funció d'un límit prefixat, sinó del parer dels secretaris de l'aljama: els capítols del lloguer de la sinagoga i de les festivitats pasquals:

in quibus sumptibus scole sive sinoge et festivitatum paschalium solvere et contribuere promito partem me in eisdem solvere contingentem ad iudicium et cognitionem vestri, dictorum secretariorum et successorum vestrorum in officio vestro secretarie (doc. 1a).

En l'acord de Salomó Vidal i del seu gendre Benvenist Rossell s'apliquen les mateixes partides fiscals acordades per a Jucef Vidal, només que l'aportació econòmica és el doble: 30 sous. En cap moment el document especifica que es tracti de dues aportacions individuals de 15 sous cada una, sinó d'una aportació comuna de 30 sous. Ara bé, fins i tot així, és òbvia l'equivalència entre aquesta quantitat i la de Jucef Vidal.

En els documents de Maimó Samuel la quantitat anual és una altra vegada de 15 sous. En el seu cas sembla que aquesta suma de diners, a diferència del que passava amb Jucef Vidal, Salomó Vidal i Benvenist Rossell, incloïa tota la càrrega contributiva anual:

ab omnibus et singulis violariis, cenis, tributis et aliis quibuscumque exactionibus regalibus et vicinalibus et aliis missionibus et expensis dictam aliamam per dictum tempus quomodolibet solvere contingentibus quocumquemodo et quacumque ratione seu causa (doc. 4).

De tota manera, en el document complementari al seu acord s'estipula que en cas que traslladés el seu domicili a Manresa, llavors hauria de contribuir a criteri de qui en el moment de signar l'acord era el secretari:

non obstante pacto predicto, [...] in predictis violariis, cenis, tributis et aliis exactionibus regalibus et vicinalibus dictam aliamam 
solvere quomodolibet contingentibus et in quibuscumque sumptibus et missionibus eiusdem aliame partem me in ipsis solvere contingentem ad iudicio et cognitione vestri dicti Baroni Juceffi non ut secretario sed ut privata persona (doc. 5$)^{56}$.

Les contribucions anuals de Bellsom Escapat són superiors a les dels documents anteriors, ja que oscil·len entre 20 sous per a cada un dels dos primers anys, i 30 sous per a cada un dels tres darrers. Aquestes quantitats incloïen el que li pertocava pagar per:

questiis, prestitis, talliis et aliis quibuscumque exactionibus regalibus et in tributis et aliis sumptibus et missionibus regalibus et vicinalibus et quibuscumque aliis dicte aliame et ipsam aliamam solvere contingentem per dictum tempus (doc. 6).

Ara bé, tot i tractar-se d'unes sumes més elevades, també ell, si decidia instal·lar-se a Manresa, veuria augmentada la seva contribució anual en 10 sous.

\section{DRETS DERIVATS D'AQUESTS PAGAMENTS}

\subsection{Dret a poder invertir capital en el mercat del crèdit de Manresa}

El pagament dels 15 sous anuals autoritzava Jucef Vidal a prestar fins a 1.500 sous:

per dictum tempus possim negotiari in civitate Minorise et in eius circumvicino faciendo ibi mutua et alia prout michi expediens fuerit cum mille quingentis solidis barchinonensibus (doc. 1a); per dictum tempus possim mutuare et negotiari in dicta civitate Minorise et quoscumque contractus quos voluero facere et inire ibidem cum mille quingentis solidis barchinonensibus (doc. 1b); adducam ad dictam civitatem hinc ad dictum festum mille D solidos cum quibus negotiabor in civitate Minorise

${ }^{56}$ L'afegitó final non ut secretario sed ut privata persona, potser s'hagi d'entendre en funció de si existien altres clàusules no posades per escrit, que només ells dos coneixien. Si Maimó Samuel es traslladava a Manresa quan Jucef Baró ja no era secretari, qui fos que llavors ocupés aquest càrrec no disposaria de tota la informació i per tant, s'hauria de recórrer a l'antic secretari per decidir com actuar en aquell cas. 
et termino Bagiarum et etiam alibi ubicumque et ex predictis videbitur (doc. 1c).

Si ultrapassava aquella quantitat, la part excedent tributava a raó de 10 sous per cada 1.000 diners ( $«$ ad rationem decem solidorum pro milenario denariorum»), és a dir, al $12 \%$.

La xifra de capital es duplica per a Salomó Vidal i el seu gendre: 3.000 sous («possimus negotiari cum tribus mille solidis barchinonensibus», doc. 2), tal com també s'havia duplicat la quantitat amb què els dos havien de contribuir a Manresa: 30 sous. En el seu cas es manté la proporció que havia aparegut en el doc. 1, en el qual s'emmiralla. També a l'hora de gravar qualsevol quantitat que excedís els dits 3.000 sous, el notari indicà que es fes com en el doc. 1 (fiat ut supra). Entenem per tant que, en aquest supòsit, la raó devia ser també del 12\%.

En el cas de Maimó Samuel no s'especifica cap quantitat, només s'indica que el capital havia de ser seu: «illarum peccunie quantitatum mearum cum quibus negotiabor in dicta civitate Minorise» (doc. 5). L'origen del capital no era irrellevant. En el doc. 3 s'indica clarament que si un resident acceptava en comanda diner d'un jueu foraster i l'invertia en el mercat del crèdit manresà havia de tributar d'una manera específica per aquest concepte.

El document relatiu a Bellsom Escapat (doc. 6) és l'únic que no fa menció d'això. Ara bé, el fet que s'hi planteja: que algú arribi a contribuir als tributs d'una aljama on no resideix, només s'explica si hi desenvolupa algun tipus d'activitat econòmica.

\subsection{Dret a un gravamen reduït sobre l'activitat econòmica}

En virtut de l'acord pres, les autoritats de l'aljama es comprometien a no exigir a l'altra part una suma de diners diferent de la pactada durant tot el temps que l'acord fos vigent. Possiblement perquè aquella quantitat era inferior de la que hagués resultat d'aquell mateix volum de capital si se li hagués aplicat el barem habitual amb què a Manresa tributava el capital foraster invertit en crèdits. 15 o 30 sous anuals per un total de $1.500 \mathrm{o}$ 3.000 sous respectivament, equivalia a un $1 \%$ del capital prestat. 
Només en un altre context contributiu trobem també gravada l'activitat creditícia de capital foraster: en els capítols de la cisa d'algunes comunitats jueves. Com a la cisa que s'aplicava a l'aljama de Tarragona (1316) i possiblement també a la de Barcelona ${ }^{57}$, i a les cises de les comunitats de Morvedre (1327) ${ }^{58}$, Castelló d'Empúries (1392) ${ }^{59}$ i Girona (1414) ${ }^{60}$. Malauradament no disposem de cap notícia tan explícita d'una cisa a l'aljama de Manresa, encara que un document del LS sembla al·ludir-hi quan esmenta els impostos que requeien sobre jueus forasters: «la quantitat en la qual algun forester o foresters de la dita aljama seran tatxats» ${ }^{61}$, com també sembla que ho facin les tributacions específiques pel capital foraster invertit a Manresa a través de jueus locals contingudes al doc. $3^{62}$.

En les ordinacions de Tarragona (i Barcelona) només es graven els crèdits concedits a dins o fora de la ciutat per jueus residents, i no es diu res dels crèdits concedits a Tarragona (i a Barcelona) per jueus forasters. En canvi en les ordinacions de Morvedre i Castelló d'Empúries, jueus residents i forasters són gravats per haver prestat en aquells llocs. El caire massa genèric del document de Girona no permet determinar la pràctica que s'hi duia a terme. En l'únic lloc on no es graven els crèdits que jueus residents havien concedit fora de la jurisdicció de l'aljama era a Castelló d'Empúries ${ }^{63}$.

${ }^{57}$ Els capítols de la cisa tarragonina s'inspiren en els de l'aljama de la Ciutat Comtal, J. Morelló, «En torno a la presión fiscal», ps. 317-329 i 345-347.

${ }^{58}$ A. Chabret, Sagunto. Su historia y sus monumentos (Barcelona 1888), tom II, doc. VIII.

${ }^{59}$ M. Pujol, «Dues tabes», ps. 7-52.

${ }^{60} \mathrm{~J}$. RIERA, Els jueus de Girona, doc. 69.

${ }^{61}$ Composició amical entre diversos jueus de Manresa, ACBG, LS, f. 2v (1/12/1342).

${ }^{62}$ No seria tan estrany que l'aljama de Manresa hagués aplicat aquest tipus d'imposició indirecta ja que la documentació relativa a la seva organització fiscal demostra que en la resta de contribucions funcionava com les altres comunitats jueves, M. C. MAÑ́; G. EsCrIBÀ, Regesta of the Cartas Reales. Part II: 1328-1493, docs. 730, 732 i 736 (1333).

${ }^{63}$ Només en cas de morositat fiscal es podia reclamar la tributació pertinent a l'activitat duta a terme amb aquell capital: «Ítem hem acordat que tot particular que treurà cabals fora de la nostra contribució, tant si resideix dins el Comtat com fora, tota vegada que no haurà pagat la seva part dels deutes de la comunitat -segons la quantitat manifestada en poder de la comunitat en aquell moment- $\mathrm{i}$ hi haurà escrit els cabals trets dels límits de la nostra contribució, estarà obligat a declarar i a pagar als senyors de l'ajuda tot el que 
Penso que aquestes dades són rellevants a l'hora de determinar l'existència d'avantatges fiscals en un context (segle XIV) en què la inversió de capital en el mercat del crèdit de diner era vista encara com una opció atractiva a l'hora d'obtenir guanys ${ }^{64}$.

Per una altra banda, tot i que es tracti de conceptes diferents, ja que una cosa són els gravàmens sobre capital foraster de les cises i una altra, la contraprestació econòmica per invertir capital en una aljama on no es resideix, pot ser interessant complementar la ràtio d'aquests contractes amb les raons que s'aplicaven a les cises per tenir una visió més completa del pes contributiu que aquestes inversions tenien en la fiscalitat de les aljames medievals.

A l'aljama de Tarragona (i de Barcelona) la raó era d'un 0,83\% si els préstecs es feien amb penyora o béns immobles, i d'un 1,6\% si eren amb interès $^{65}$. A l'aljama de Morvedre era també d'un $0,83 \%$ si es tractava de préstecs amb penyora, i d'un $1,25 \%$ si eren amb interès ${ }^{66}$. A la comunitat

haurà fet amb ells dins aquest bisbat, i això sots pena i el jurament esmentats», M. PuJoL, «Dues tabes», art. VI, p. 22.

${ }^{64}$ J. Hinojosa, «El préstamo judío en la ciudad de Valencia en la segunda mitad del siglo XIV», Sefarad 45:2 (1985) ps. 315-339; G. TodeschInI, La richezza degli ebrei. Merci e denaro nella riflessione ebraica e nella definizione cristiana dell'usura alla fine del medioevo (Spoleto 1989); A. Furió, «Endettement paysan et crédit dans la péninsule Ibérique au bas moyen âge», en Endettement Paysan \& Crédit Rural dans l'Europe médiévale et moderne, ed. M. Berthe (Toulouse-Le Mirail 1998) ps. 139-167; J. Shatzmiller, Shylock revu et corrigé. Les juifs, les chrétiens et le prêt d'argent dans la société médiévale (París 2000); C. DenJeAn, La loi du lucre. L'usure en procès dans la couronne d'Aragon à la fin du moyen âge (Madrid 2011).

${ }^{65}$ «Primerament, que tot juheu e tota juhia estadant de Tarragona que prest per sí ni per altra a usura en Tarragona o en altre qualche loch, que pach IIII drs. pro libra; e si per ventura prestava o fahia prestar sobre penyores, pach II drs. pro libra [...] Item, que aquell qui prestarà sobre alberch, que pach II drs. pro libra de ço que hi prestarà», J. Morelló, «En torno a la presión fiscal», ps. 345 i 347.

${ }^{66}$ A Morvedre s'apliquen les mateixes raons tant si els crèdits s'havien concedit a dins com a fora de la vila: «Ítem que tot juheu et juya estrany o privat qui en la dita vila o terme d'aquella prestarà o farà prestar a crestià o a sarrahins o encara comenarà a logra o a usura ab carta o ab obligació de pena de quart o sens aquelles, sie tengut a pagar a la dita aiuda per quescuna libra que prestarà del cabal contengut en la carta, tres diners. E si alcun juheu o juya estadant en la dita vila et terme d'aquella fore la vila e terme prestarà $o$ comanarà o farà prestar o comanar a logra e a usura o menys de logre et de usura ab carta o obligació de pena de quart o sens aquelles sie que faça dir la carta e nom seu o en nom 
de Castelló d'Empúries, l'activitat creditícia es gravava al 2,5\% . A Girona, l'any 1414 , la infanta Violant reformà la ràtio impositiva sobre el capital invertit en deutes per tal que l'aljama pogués recaptar més diners amb què fer front als pagaments anuals a què estava obligada (sobretot pensions de censals), fixant la raó al $4 \%{ }^{68}$.

L'1\% dels acords del LS es manté per sota de les ràtios previstes per als crèdits amb usura i lleugerament per sobre de les ràtios dels crèdits amb penyora. El fet però, de no disposar de la cisa de l'aljama de Manresa fa que sigui impossible determinar si l'1\% d'aquests contractes diferia gaire dels tipus de les imposicions indirectes. De tota manera, l'increment de l' $1 \%$ fins al $12 \%$ que s'aplicava de manera automàtica quan s'excedia el límit de capital acordat entre les parts, avalaria la interpretació segons la qual 1'1\% devia ser una raó moderada.

\section{FinALITAT D’aQUESTES פשרות}

Els documents que presentem aquí són acords fiscals pactats entre els secretaris de torn de l'aljama de Manresa i un o diversos jueus d'altres municipis. Aquests acords contenen deduccions fiscals pensades per a jueus estrangers que volien invertir capital en el mercat del crèdit de diner manresà. La possibilitat que s'establissin a la ciutat no hi és negada, però en cap cas és presentada com una condició necessària. D'altra banda, segons una dinàmica que es repeteix en alguns d'aquests documents, la hipòtesi d'una domiciliació a Manresa del jueu foraster comportava un enduriment de les condicions pactades en l'acord. Es pot concloure doncs, d'entrada, que aquests acords no formaven part de cap estratègia

d'altra persona crestiana, juheu o sarrehi, pac la dita aiuda en la forma damunt dita», A. Chabret, Sagunto, tom II, doc. VIII, p. 415.

${ }^{67}$ «Tot home o tota dona amb qui un cristià o una cristiana contraurà un deute mitjançant instrument debitori, carta de comanda, albaran, dita de canviador o dita de clavari d'aquesta vila, pagarà, per cada lliura, sis diners, i així segons més o segons menys», M. PuJoL, «Dues tabes», art. I, p. 21.

68 «Tots ensemps o la major partida de vosaltres imposets vuytanta sol. per millenar, ço és, quaranta sol. en les egualtats de les imposicions dels deutes, e altres XL sol. de talla, e més avant un fogatge e una talla de guanyatges», J. RiERA, Els jueus de Girona, doc. 69, p. 300. 
seguida per les autoritats de l'aljama per incentivar l'emigració de població jueva cap a Manresa.

Els documents estudiats s'entenen millor com una manera d'atreure capital foraster cap a Manresa a través d'uns tipus impositius reduïts. L'activitat creditícia, que encarrilava la inversió d'aquest capital estranger, es correspon perfectament a la dimensió que els crèdits amb usura encara tenien, durant les dècades dels anys 30 i 40 del segle XIV, en diversos municipis catalans ${ }^{69} \mathrm{i}$ que en el cas de Manresa, es va perllongar fins a finals de segle ${ }^{70}$.

La necessitat d'atreure capital foraster a Manresa i els impostos que hi anaven associats es justificaria per la forta pressió fiscal a què estava sotmesa l'aljama i els seus responsables.

En efecte, les contribucions reials documentades al LS són elevades i no inclouen pas tots els impostos i exaccions als quals va haver de fer front la comunitat de Manresa en aquells anys. A aquestes partides s'hi han d'afegir encara les despeses ordinàries del funcionament de l'aljama i de les seves institucions, de les quals el LS gairebé no aporta cap xifra però en documenta l'existència i sobretot la cura dels responsables per finançar-les.

En un context marcat per les demandes pecuniàries de la Corona i per la reestructuració de la comunitat (Manresa es va separar de la col·lecta de Barcelona l'any 1341), els secretaris de l'aljama van promoure uns acords amb jueus forasters que, a la vegada que injectaven liquiditat en el mercat del crèdit manresà, repercutien profitosament en les finances de la comunitat ${ }^{71}$. O no estava inclòs aquest concepte en la cisa de la co-

${ }^{69}$ A. García, «Los intereses en los préstamos de los judíos de Vich durante la primera mitad del siglo XIV», Ausa 41 (1962) ps. 247-255; M. CASAS, «El "Liber iudeorum" de Cardona (1330-1334). Edició i estudi», Miscel-lània de textos medievals 3 (1985) ps. 119314 i 327-345; E. MATEu, «Aproximació als préstecs jueus de Tortosa: la figura de Bafaya Aquiva (segle XIv)», Recerca 5 (2001) ps. 121-139; T. AleIXANDre, El Liber Iudeorum núm. 90 de l'Aleixar (1344-1348). Estudi i edició (Barcelona 2004); J. X. Muntané, Regest dels documents de l'Arxiu Parroquial de Verdú relatius als jueus (1265-1484) (Barcelona 2015), vol. 1, ps. CII-CLXXV.

${ }^{70}$ J. X. Muntané, «El testament i l'inventari d'Astruc Iossef»; M. C. Mañé; G. Escribà, Regesta of the Cartas Reales. Part II: 1328-1493, doc. 1282 (14/8/1405).

${ }^{71}$ Les mesures contributives estan en íntima relació amb la pressió fiscal i les dificultats financeres no només de les aljames sinó també dels municipis cristians, P. 
munitat (com l'any 1319 passava a Barcelona i Tarragona on no es diu res de creditors jueus forasters) o no existia cisa a l'aljama de Manresa. Tant en un cas com en l'altre, aquests contractes venien a suplir en certa manera aquesta mancança. Ara bé, si es donava el cas que a l'aljama de Manresa ja existia una cisa que inclogués aquest concepte (recordem «la quantitat en la qual algun foraster o forasters de la dita aljama seran tatxats», ACBG, LS, f. 2v), qui sap si llavors una de les finalitats que es perseguia amb aquests acords, a més d'incrementar amb aquesta variant contributiva les entrades provinents de capital foraster durant els períodes de vigència dels acords, no podria ser també la d'atreure nous inversors a Manresa a través d'unes taxes reduïdes per fidelitzar aquell capital de cara a futures contribucions.

Des del punt de vista de l'altra part, de l'inversor jueu foraster, és possible que la pèrdua que li ocasionava la ràtio que havia de pagar pel capital (tant la inicial o moderada com la que s'aplicava un cop s'havia superat la suma de capital acordada) no només vingués compensada pel benefici que es derivava dels interessos dels préstecs, sinó també perquè la inversió de capital fora del lloc de residència es podia convertir en un mecanisme per evadir una part del capital al peatge fiscal de la seva comunitat.

El control sobre aquests moviments de capital depenia principalment de la paraula i de la predisposició de l'inversor a manifestar-los, cosa que ningú ni res podia garantir. Les amenaces d'excomunió, l'obligació de prestar jurament en cas que així li fos requerit i les multes eren els mecanismes de control i de càstig habituals per conjurar el risc d'evasió fiscal ${ }^{72}$.

Finalment, la contribució a les despeses comunals de Manresa que s'acordava amb aquests inversors de fora, no és fàcil d'interpretar. Pot

VERDÉs, «Les imposicions a Cervera durant la segona meitat del s. XIV», en Col-loqui Corona, Municipis i Fiscalitat a la Baixa Edat Mitjana: actes, coords. M. SÁnchEZ, A. Furió i P. BERTRAN (Lleida 1997) ps. 421-422.

${ }^{72}$ També en el document de Jucef Vidal, ell i la seva dona s'obliguen a prestar jurament per les quantitats prestades a Manresa sempre que els secretaris d'aquella aljama els ho demanin: «Et quod ego et uxor mea habeamus et teneamur prestare sacramentum in posse vestri dictorum secretariorum et succesorum vestrorum in dicto officio totiens quotiens inde requisiti fuerimus verbo, nuntio vel scripto de eo scilicet cum pluri peccunie quantitate preterquam cum dictis mille quingentis solidis negotiemur in dicta civitate sive non» (doc. 1a). Sobre frau fiscal en relació al pagament de taxes, Y. T. Assis, Jewish Economy, ps. 107-110. 
ser que en aquest cas, el document s'emmiralli en els típics documents de veïnatge, o que es pugui justificar com una contrapartida pels avantatges que aquests jueus forasters obtenien de certes institucions o persones de la comunitat a l'hora de negociar a Manresa (privilegis de l'aljama, relacions amb l'entorn cristià, instal-lacions de la sinagoga, personal determinat de la comunitat, etc.).

\section{DOCUMENTS}

El criteri de presentació dels documents és cronològic. Cada document ve precedit per la data, el tipus documental, un breu resum del contingut i la localització. A l'aparat crític que hi ha al seu final, s'hi recullen les correccions, supressions, afegits, anotacions liminars, etc. El text original figura sempre en rodona i els comentaris editorials, en cursiva. Per a la transcripció he optat per desenrotllar les abreviatures bo $\mathrm{i}$ adequant les grafies $\langle\mathrm{c} / \mathrm{t}\rangle,<\mathrm{v} / \mathrm{u}\rangle \mathrm{i}<\mathrm{i} / \mathrm{j}\rangle \mathrm{d}$ 'acord amb l'hàbit de l'escrivà. Regularitzo l'alternança de la $<\mathrm{c}>\mathrm{i}<\mathrm{c}>$ davant $<\mathrm{a}, \mathrm{o}, \mathrm{u}>$, per evitar confusions atès que els escrivans sovint negligeixen la titlla de la ç. Regularitzo l'ús de majúscules i minúscules, puntuo els textos i separo els mots segons l'ús modern, sempre que això no entri en contradicció amb els usos medievals.

\section{1a}

22 de gener de 1343

Pacte acordat entre Jucef Vidal, jueu de Vic, d'una banda, i els secretaris de l'aljama de Manresa, Baró Jucef i Rovén Salomó, de l'altra banda, referent a la participació del jueu estranger a les contribucions de l'aljama derivada de l'activitat econòmica duta a terme per ell a la ciutat i terme de Manresa. L'acord és vàlid fins a la festa de St. Miquel (29 de setembre) $i$ a partir d'aquella data, durant dos anys sencers.

ACBG, Liber secretariorum aliame Minorise (1343-1353), fs. 3v-4r

${ }^{1}$ Undecimo kalendas ffebruarii anno Domini $\mathrm{M}^{\circ} \mathrm{CCC}^{\circ} \mathrm{XL}$ tertio.

Juceffus $^{2}$ Vitalis, judeus nunc comorans in civitate vicensi, cum testimonio huius publici instrumenti promito et convenio bona fide et 
per firmam et legalem stipulationem vobis, Barono Juceffi et Rovent Salomonis, judeis Minorise ac secretariis aliame judeorum Minorise, recipientibus nomine dicte aliame et judeorum ipsius, quod ego hinc usque ad primum venturum festum sancti Michaelis septembris et ab ipso festo sancti Michaelis septembris usque ad duos annos primos venturos et completos, solvam et contribuam de bonis meis in quolibet trauto ex trautis que per dictam aliamam solventur per dictum tempus et quorum trautorum quodlibet est mille septingentorum solidorum, quindecim solidos barchinonenses. Et etiam solvam et contribuam de bonis meis in omnibus et singulis sumptibus et missionibus qui per dictum tempus fieri per dictam aliamam sint, sive regalibus sive vicinalibus, partem me in ipsis solvere contingentem pro solido et libra pro rata videlicet dictorum quindecim solidorum quos in quolibet dictorum trautorum tenear solvere et contribuere per dictum tempus ut superius continetur. In predictis autem sumptibus et missionibus non intelliguntur sumptus fiendi per dictam aliamam per predictum tempus in logerio scole sive sinoge dicte aliame nec in festivitatibus paschalibus, in quibus sumptibus scole sive sinoge et festivitatum paschalium solvere et contribuere promito partem me in eisdem solvere contingentem ad iudicium et cognitionem vestri, dictorum secretariorum et successorum vestrorum in officio vestro secretarie. Ego autem per dictum tempus possim negotiari in civitate Minorise et in eius circumvicino faciendo ibi mutua et alia prout michi expediens fuerit cum mille quingentis solidis barchinonensibus, pro quibus nec etiam aliis per dictum tempus possim tatxari seu talliari per vos vel successores vestros in dicto vestro officio, nec per alium seu alios quemcumque vel quoscumque in dicta civitate Minorise, nec etiam alibi nisi prout superius continetur. Excepto quod si forte ego cum pluri peccunie quantitate preterquam cum dictis mille quingentis solidis sive sit mei sive alteri ${ }^{3}$ voluero per dictum tempus negotiari in dicta civitate et eius circumvicino, tenear pro ipso pluri solvere et contribuere in quolibet dictorum tributorum ${ }^{4}$ et in aliis exactionibus supradictis pro rata videlicet ipsius pluri, scilicet ad rationem decem solidorum pro milenario denariorum. Et quod ego et uxor mea habeamus et teneamur prestare sacramentum in posse vestri dictorum secretariorum et succesorum vestrorum in dicto officio totiens quotiens inde requisiti fuerimus verbo, nuntio vel scripto de eo scilicet 
cum pluri peccunie quantitate preterquam cum dictis mille quingentis solidis negotiemur in dicta civitate sive non. Et quod de hiis stetur juramento mei et uxoris mee predicte quam siquidem promissionem omnium predictorum et singulorum vobis dictis secretariis facio sicut melius et cetera. Et pro predictis obligo et cetera; renuntio et cetera; renuntio et cetera. Et etiam renuntio foro meo et cetera, foro /f. 4r/ et jurisdictioni vicarii et baiuli Minorise. Ad hec nos, Baronus ${ }^{5}$ Juceffi et Rovent $^{6}$ Salomonis, secretarii predicti, consentientes predictis et recipientes presentem promissionem a vobis dicto Juceffo Vitalis sub conditionibus supradictis, laudamus et firmamus hec, et promitimus et convenimus vobis eidem Juceffo Vitalis quod nobis solventem per dictum tempus in quolibet tributo et in aliis missionibus regalibus et vicinalibus dicte aliame, partem vos in eisdem solvere contingentem, secundum formam predictam, nos faciemus ${ }^{7}$ vos quitium et immunem a contributione, questie et aliarum missionum et quarumcumque exactionum que a vobis peti possent vel a vobis exigi pro questia, servitio et pro alia quacumque exactione quocumque nomine censeatur ratione peccunie cum qua negotiabimini in civitate Minorise et eius circumvicinio per totum dictum tempus. Et a predictis nos et bona nostra servabimus penitus sine dampno. Ita quod si aliquod sustinueritis dampnum et cetera, credatur nobis et cetera. Et pro predictis attendendis et cetera, obligamus vobis et vestris omnia bona dicte aliame quecumque sint et fuerint et ubique; et renuntiamus et cetera. Testes Ffranciscus Granoya et Petrus de Pulcrosolano, cives Minorise, et Astrugus Juceffi, judeus ${ }^{8}$.

1. Escrit al marge superior del foli, Anno, sense indicació d'any. Al marge esquerre f. 3v, XII denarios. 2. Dues ratlles obliqües al damunt en senyal de ferma. 3. sive sit mei sive alteri, interlineat. 4. Segueix et aliarum exactionum predictarum, ratllat. 5. Dues ratlles obliqües al damunt en senyal de ferma. 6. Dues ratlles obliqües al damunt en senyal de ferma. 7. Segueix vobis, ratllat. 8. Nòtula cancel-lada amb quatre línies inclinades. Afegit a continuació, Sint duo. Die lune, intitulata $\mathrm{VI}^{\circ}$ mensis madii anno Domini millesimo $\mathrm{CCC}^{\circ} \mathrm{XL}^{\circ}$ quinto, de mandato Astrugi Jucefi, judei Minorise, secretarii aliame judeorum Minorise electi per dominum regem cum eius littera papirea, fuit cancellatum, de voluntate etiam dicti Jucefi Vitalis. 
Alf. 1v figura una còpia d'aquest document, inacabada, que transcrivim a continuació:

Undecimo kalendas ffebruarii anno Domini $\mathrm{M}^{\circ} \mathrm{CCC}^{\circ} \mathrm{XL}$ tertio.

Juceffus Vitalis, judeus nunc comorans in civitate vicensi, cum testimonio huius publici instrumenti promito et convenio bona fide et per firmam et legalem stipulationem vobis, Barono Juceffi et Rovent Salomonis, judeis Minorise ac secretariis aliame judeorum Minorise, recipientibus nomine dicte aliame, quod ego hinc ad primum venturum festum sancti Michaelis septembris et ab ipso festo sancti Michaelis septembris proximo venturo usque ad duos annos primo venturos et completos, dabo et solvam in quolibet trauto trautorum quod dicta aliama dare et solvere tenetur domino regi, quorum trautorum ${ }^{1}$ quodlibet est mille septingentorum solidorum, quindecim solidos barchinonenses. Et etiam solvam et solvere promito per dictum tempus in omnibus et singulis sumptibus ${ }^{2}$, cenis et aliis quibuscumque exactionibus regalibus et vicinalibus quocumque nomine censeatur partem me in ipsis solvere contingentem pro solido et libra sive pro rata dictorum quindecim solidorum quos in quolibet dictorum trautorum solvere teneor per dictum tempus prout superius continetur. In predictis autem ${ }^{3}$ sumptibus non intelliguntur sumptus fiendi per dictum tempus in festivitatibus paschalibus nec in logerio seu logeriis sinoge sive scole dicte aliame, in quibus missionibus dictarum festivitatum et dicte sinoge $e^{4}$ sive scole tenear ponere et mittere partem me in ipsis solvere contingentem ad cognitionem vestram vel sucessorum vestrorum in dicto officio vestro secretarie. Ego autem per dictum tempus possim mutuare et negotiari in dicta civitate Minorise et quoscumque contractus quos voluero facere et inire ibidem cum mille quingentis solidis barchinonensibus, pro quibus sive ratione quorum nec etiam aliis non possim aliqui in dicta civitate Minorise nec etiam alibi pro ipsis mille D solidis compelli ad dandum seu contribuendum aliqui aliud per dictum tempus nisi ut superius continetur. Salvo tamen a vobis retento quod si ego cum pluri peccunie quantitate preterquam ${ }^{5}$.

1. Segueix quodlibet, ratllat. 2. sumptibus, interlineat. 3. Segueix exac<tionibus $>$, ratllat. 4. Segueix vel, ratllat. 5. El text s'acaba abruptament. Nòtula cancel·lada amb una línia ondulada. 


\section{1c}

Esborrany d'aquest document conservat en un full solt del LS:

Juceffus Vitalis, judeus vicensis, cum testimonio huius publici instrumenti promito et convenio vobis, Rovent Salomonis et Barono Juceffi, judeis secretariis aliame judeorum Minorise, presentibus et cetera, recipientibus nomine dicte aliame et vobis nomine et cetera, quod hinc ad festum sancti Michaelis septembris transtulero domicilium meum in civitate Minorise et ab ipso festo sancti Michaelis ad duos annos continue primo venturos et completos tenebo et fovebo domicilium meum in civitate Minorise et adducam ad dictam civitatem hinc ad dictum festum mille $\mathrm{D}$ solidos cum quibus negotiabor in civitate Minorise et termino Bagiarum et etiam alibi ubicumque, et ex [predictis] videbitur et dabo et solvam in questiis et aliis exactionibus regalibus et vicinalibus quocumque nomine censeatur pro ipsis MD solidis ad quod sequitur, videlicet in quolibet trauto quod est mille DCC solidorum quod per dictam aliamam solventem per dictum tempus duorum annorum, XV solidos barchinonenses. Et si sumptus et cetera, ad me. In hec non intelliguntur sumptus Pasche et sinoge, in quibus taxiari possim ad judicium secretariorum. ${ }^{1}$ Si vero ego ultra dictos mille D solidos adducere voluo et cum ipsis negotiabo et cetera, tamen vobis et successoribus vestris dare in quolibet dictorum trautorum [pro] quolibet [milenario], $\mathrm{X}$ solidos, et sic secundus $\mathrm{M}$ [...] pro rata scilicet $\mathrm{X}$ solidos pro $\mathrm{M}$ denariorum in hanc anno [...] et cetera; sicut vobis et cetera. Et pro predictis obligo et cetera; renuntio et cetera; ad hec nos et cetera; promitimus vobis dare et cetera; quod nobis solvente et cetera; $[. .$.$] obligamus et cetera; quisque et cetera;$ renuntiamus et cetera ${ }^{2}$; obligamus et cetera. Testes ${ }^{3}$.

1. Et si sumptus et cetera; ad me. In hec non intelliguntur sumptus Pasche et sinoge, in quibus taxiare possim ad judicium secretariorum, interlineat. 2. renuntiamus et cetera, interlineat. 3. Afegit a sota, Item Salomonus Vitalis III mille solidos per se et Benvenist Rosselli, veg. doc. 2. Esborrany cancel-lat amb tres línies inclinades. 
22 de gener de 1343

Pacte acordat entre Salomó Vidal, jueu de Vic, en nom seu i del seu gendre Benvenist Rossell, d'una banda, $i$ els secretaris de l'aljama de Manresa, Baró Jucef i Rovén Salomó, de l'altra banda, referent a la participació dels jueus estrangers a les contribucions de l'aljama derivada de l'activitat econòmica duta a terme per ells a la ciutat i terme de Manresa. L'acord és vàlid fins a la festa de St. Miquel (29 de setembre) i a partir d'aquella data, durant dos anys sencers.

ACBG, Liber secretariorum aliame Minorise (1343-1353), f. 4r

Salomonus ${ }^{1}$ Vitalis, judeus comorans nunc in civitate vicensi, agens in hac parte nomine meo proprio et etiam nomine et pro parte Benvenist Rosselli, judei, generi mei, promito per firmam et legalem vobis, dictis secretariis, recipientibus nomine quo supra ${ }^{2}$, quod hinc usque ad primum venturum festum sancti Michaelis septembris et ab ipso festo santi Michaelis septembris usque ad duos annos primo venturos et completos, ego et dictus generus meus solvemus et contribuemus de bonis nostris in quolibet trauto trautorum predictorum, triginta solidos barchinonenses, et in aliis sumptibus ut supra. Et possimus negotiari cum tribus mille solidis barchinonensibus. Et si cum pluri peccunie quantitate negotiabimus et cetera. Fiat ut supra. Ad hec nos Baronus ${ }^{3}$ Juceffi $^{4}$ et Rovent ${ }^{5}$ Salomonis, secretari predicti, consentientes et cetera. Fiat ut supra. Testes qui supra.

1. Dues ratlles obliqües al damunt en senyal de ferma. 2. Per a aquesta i les altres vegades que el document es remet a un document previ, veg. doc. la i doc. 1c nota 3. 3. Dues ratlles obliqües al damunt en senyal de ferma. 4. Segueix et As<truch>, ratllat. 5. Dues ratlles obliqües al damunt en senyal de ferma.

27 d'agost de 1345

Permís de residència temporal a Manresa acordat entre el jueu Astruc Bonjua, d'una banda, i jueus representants de l'aljama (els germans Baró Jucef i Astruc Jucef, Rovén Salomó i Vidal Astruc Adret, jueus de Manresa). L'acord té una validesa de 5 anys. 
ACBG, Liber secretariorum aliame Minorise (1343-1353), f. 12r-v

${ }^{1} \mathrm{VI}^{\circ}$ kalendas septembris anno Domini millesimo $\mathrm{CCC}^{\circ} \mathrm{XL}^{\circ} \mathrm{V}^{\mathrm{o}}$

Astrugus ${ }^{2}$ Bonjuha, judeus, cum testimonio huius publici instrumenti promito et convenio bona fide ac firma et legali stipulatione vobis, Barono Jucefi et Astrugo Jucefi, fratribus, Rovent Salomonis et Vitali Astrugi Adreti, judeis Minorise, nominibus vestris et aliorum judeorum aliame Minorise hoc recipientibus et acceptantibus, quod hinc ad quinque annos primo continue $/ 12 \mathrm{v} /$ venturos et completos contribuam in negotiis dicte aliame per modum inferius declaratum videlicet quod anno quolibet dictorum $\mathrm{V}$ annorum ${ }^{3}$ solvam et tradam dicte aliame vel $^{4}$ eius secretariis ratione videlicet questiarum, tributorum et aliarum quarumcumque exactionum regalium aut vicinalium nec non quarumcumque missionum ${ }^{5}$ et expensarum paschalium et scole, et quarumlibet etiam aliarum que infra dictum tempus quinque annorum per dictam aliamam fient aut aliter pro eadem aliama seu occasione eiusdem et eius negotiorum ${ }^{6}$ quomodocumque et qualitercumque subsequte fuerunt, triginta solidos barchinonenses, de quibus solvam anno ${ }^{7}$ quolibet dicti temporis in festo Natalis Domini medietatem, et aliam medietatem in festo sancti Johannis Babtiste. Pro quibus per me vobis attendendis et cetera; obligo et cetera; renuntio et cetera; et juro per Deum et decem precepta legis que Deus dedit Moysi et cetera, predicta attendere et cetera $^{8}$. Ad hec nos, Baronus ${ }^{9}$ Jucefi et Astrugus ${ }^{10}$ Jucefi, fratres, Rovent ${ }^{11}$ Salomonis et Vitalis ${ }^{12}$ Astrugi Adreti, judei Minorise, agentes in hiis nominibus nostris propriis et aliorum dicte aliame judeorum, consentientes predictis, promitimus et convenimus bona fide ac firma et valida stipulatione vobis, Astrugo ${ }^{13}$ Bonjuhe, judeo predicto, quod nos et dicta aliama mantenebimus et defendemus vos et bona vestra sicut alios judeos ipsius aliame. Et volumus et consentimus expresse quod vos, idem judeus, per dictum tempus non solvatis aut solvere seu contribuere teneamini in negotiis et sumptibus dicte aliame vel aliis predictis aliquid aliud nisi tantum et dumtaxat annuatim eiusdem temporis per terminos antedictos, triginta solidos antedictos. Immo ${ }^{14}$ vobis solvente ipsos ab aliis omnibus supradictis sitis immunis penitus atque ${ }^{15}$ liber, et gaudeatis per dictum tempus quibuscumque privilegiis dicte aliame indultis quomodolibet et concessis sicut unus ex aliis judeis dicte alia$\mathrm{me}^{16}$. Et quod finito predicto tempore ${ }^{17}$ in casu tamen quod de predictis 
per vos aliquid non debeatur, dicte aliame possitis et libere valeatis ${ }^{18}$ dictam aliamam dimitere et ubilibet cum bonis vestris ${ }^{19}$ ire et stare absque nostri et dicte aliame obstaculo et impedimento. Pro predictis autem obligamus et cetera; renuntiamus et cetera. Verumtamen si infra dictum tempus vos recepitis aliquid in comanda ab aliquo seu aliquibus aut aliquis seu aliqui, extra Minorisam degentes ${ }^{20}$, $^{21}{ }^{21}$ dictum tempus ${ }^{22}$ vobis aliquid comandaverint seu tradiderint pro lucrando de eis in dicta civitate Minorise et de ipsis negotiatus fueritis in civitatem eadem, teneamini exinde per jamdictum tempus contribuere pro solido et libra eorundem que $a b^{23}$ extraneis tenueritis, ut prefertur in civitate prefata, sicut unus ex judeis dicte aliame, antequam vos cum dictis bonis vestris dictam civitatem Minorise presumatis exire, cum ita ex nunc actum sit comprehensum et in pactum deductum inter vos, ex una parte, et nos, ex altera. Testes Periconus de Gostemps et Ffranciscus Rubei.

1. Al marge superior del document, escrit en majúscules, Anno Domini $\mathrm{M}^{\circ} \mathrm{CCC}^{\circ} \mathrm{XL}^{\circ}$ quinto. 2. Dues ratlles obliqües al damunt seguides de juro, en senyal de ferma i jurament. 3. contribuam in negotiis dicte aliame per modum inferius declaratum videlicet quod anno quolibet dictorum $\mathrm{V}$ annorum, interlineat. 4. Segueix dicte, ratllat. 5. Segueix seu ex, ratllat. 6. Afegit al marge esquerre. 7. Segueix in festo $\mathrm{N}<$ atalis $>$, ratllat. 8. Segueix obligo, ratllat. 9. Dues ratlles obliqües al damunt, en senyal de ferma. 10. Dues ratlles obliqües al damunt, en senyal de ferma. 11. Dues ratlles obliqües al damunt, en senyal de ferma. 12. Dues ratlles obliqües al damunt, en senyal de ferma. 13. Segueix ju <deo $>$, ratllat. 14. Segueix no, ratllat. 15. Segueix liber, ratllat. 16. sicut unus ex aliis judeis dicte aliame, interlineat. 17. Segueix un mot ratlat. 18. Segueix un mot ratllat. 19. cum bonis vestris, interlineat. 20. extra Minorisam degentes, interlineat. 21. Segueix dictum, ratllat. 22. tempus, interlineat. 23. ab, interlineat.

\section{1 de gener de 1346}

Pacte acordat entre el jueu Maimó Samuel, d'una banda, i el secretari de l'aljama de Manresa, Baró Jucef, de l'altra banda, referent a la participació del dit Maimó Samuel a les contribucions de l'aljama per als propers 5 anys. 
ACBG, Liber secretariorum aliame Minorise (1343-1353), f. 15v

Pridie kalendas ffebruarii anno Domini $\mathrm{M}^{\circ} \mathrm{CCC}^{\circ} \mathrm{XL} \mathrm{VI}^{\circ}$

Maymonus ${ }^{1}$ Samuell, judeus, cum testimonio huius publici instrumenti promito et convenio bona fide et per firmam et legalem stipulationem vobis, Barono Juceffi, judeo Minorise, secretario nunc aliame judeorum Minorise, recipienti nomine dicte aliame et successorum vestrorum in officio dicte secretarie, quod ego hinc ad quinque annos primo continue venturos et completos dabo et solvam vobis ${ }^{2}$ et dictis vestris succesoribus in dicto vestro officio secretarie annuatim per dictum tempus quinque annorum, quindecim solidos barchinonenses, pro omnibus et singulis me solvere contingentibus per dictum tempus in omnibus et singulis violariis, cenis, tributis et aliis quibuscumque exactionibus regalibus et vicinalibus et aliis quibuscumque exactionibus et missionibus, de quibus quidem XV solidis dabo et solvam vobis et vestris successoribus annuatim per dictum tempus in quolibet festo santi Johannis Babtiste, VII solidos et medium, et in quolibet festo Natalis Domini, alios VII solidos et medium. Hanc autem promissionem et cetera, sicut melius et cetera. Et pro predictis obligo et cetera; renuntio et cetera. Ad hec ego, Baronus ${ }^{3}$ Jucefii, secretarius predictus, consentiens predictis, laudo et firmo hec. Et nichilominus concedo vobis, dicto Maymono Samueli, quod vobis dante et solvente michi et meis successoribus in dicto meo officio secretarie dictos XV solidos per dictos terminos, ex tunc et nunc ut ex tunc et tunc ut ex nunc sitis quitius, liber et immunis ab omnibus et singulis violariis, cenis, tributis et aliis quibuscumque exactionibus regalibus et vicinalibus et aliis missionibus et expensis dictam aliamam per dictum tempus quomodolibet solvere contingentibus quocumquemodo et quacumque ratione seu causa. Et pro predictis attendendis et cetera, obligo vobis et vestris omnia bona dicte aliame. Renuntio et cetera; et predicta omnia et singula et cetera; facimus et cetera; in posse notarii et cetera. Testes Ffranciscus Rubei et Petrus de Ratia, cives Minorise, et Astrugus Juceffi, judeus ${ }^{4}$.

1. Dues ratlles obliqües al damunt en senyal de ferma. 2. Segueix annua<tim>. 3. Dues ratlles obliqües al damunt en senyal de ferma. 4 . Nòtula cancel-lada amb una línia vertical. Al marge esquerre, XII denarios; a sota, Petrus Natale. 
1 de febrer - 4 de març de $1346^{1}$

Document complementari al pacte acordat entre el jueu Maimó Samuel i el secretari de l'aljama de Manresa, Baró Jucef, (veg. doc. 3) en què es deixa constància escrita de l'activitat econòmica i altres condicions pactades només de paraula en el dit acord.

ACBG, Liber secretariorum aliame Minorise (1343-1353), fs. 15v$16 \mathrm{r}$

Maymonus ${ }^{2}$ Samuel, judeus predictus, attendens ego deveni ad compositionem et transactionem vobiscum Barono Juceffi, judeo Minorise, secretario aliame judeorum Minorise, de dando vobis et successoribus vestris in dicto vestro officio ${ }^{3}$ singulis annis per quinquenium primum venturum quindecim solidos barchinonenses pro omnibus et singulis me solvere contingentibus per dictum /f. 16r/ tempus in omnibus et singulis violariis, ceniis, tributis et aliis quibuscumque exactionibus regalibus et vicinalibus et aliis quibuscumque dictam aliamam solvere contingentibus per dictum tempus quocumquemodo et quacumque ratione seu causa, cum ut in instrumento dicte compositionis et transactionis quod confectum est in scribania publica Minorise in kalendario pridie kalendas ffebruarii anno Domini insfrascripto, quod inter judeos sive ebrayce vocatur passara, latius continetur. Attendens etiam quod dicta compositio et transactio fuit facta de predictis inter me et vos, dictum Baronum Juceffi, acto cum et in pactum deducto verborum inter me et vos, quod predictam peccunie quantitatem dictorum XV solidorum dem et tradam vobis dicto secretario et successoribus vestris in dicto officio vestro secretarie annuatim per dictum tempus pro et ratione illarum peccunie quantitatum mearum cum quibus negotiabor in dicta civitate Minorise dum cum ego ibidem non foveam domicilium meum. Et quod si forte ego per dictum tempus quinque annorum fovebo domicilium meum in dicta civitate quod ex tunc, non obstante pacto predicto, contribuam et contribuere tenear in predictis violariis, cenis, tributis et aliis exactionibus regalibus et vicinalibus dictam aliamam solvere quomodolibet contingentibus et in quibuscumque sumptibus et missionibus eiusdem aliame partem me in ipsis solvere contingentem, ad iudicio et cognitione vestri, dicti Baroni Juceffi, 
non ut secretario sed ut privata persona. Idicirco attendens predictis que in veritate sunt et consistunt et aliis etiam que per me in hac parte videnda fuerint et etiam attendenda, cum testimonio huius publici instrumenti promito et convenio bona fide et per firmam stipulationem vobis, dicto Barono Juceffi, secretario predicto presenti et cetera, quod si forte ego per dictum tempus quinque annorum fovebo domicilium meum in civitate Minorise, ego, non obstante pacto predicto, contribuam in predictis violariis, cenis, tributis et aliis exactionibus regalibus et vicinalibus dictam aliamam solvere contingentibus judicio et cognitione vestri, dicti Baroni Juceffi, non ut secretario sed ut privata persona. Hanc autem promissionem et cetera, sicut melius et cetera. Et pro predictis obligo et cetera; renuntio et cetera ${ }^{4}$; hec igitur et cetera; in posse notario et cetera. Testes qui supra.

1. El document fou fermat en una data que desconeixem dins d'aquest període suggerit ja que, d'una banda, era posterior a la data del document que cita en el seu interior (in kalendario pridie kalendas ffebruarii) $i$, de l'altra, precedia a la data del document següent, atorgat el 5 de març (tertio nonas martii, f. 16r). 2. Dues ratlles obliqües al damunt en senyal de ferma. 3. et successoribus vestris in dicto vestro officio, interlineat. 4. Segueix Testes qui supra, ratllat; hec igitur et cetera, interlineat.

\section{6}

2 de juny de 1346

Pacte acordat entre el jueu Bellsom Escapat, d'una banda, i el secretari de l'aljama de Manresa, Baró Jucef, de l'altra banda, referent a la participació del dit Bellsom Escapat a les contribucions de l'aljama derivada de l'activitat econòmica duta a terme per ell a la ciutat i terme de Manresa. L'acord té una validesa de 5 anys.

ACBG, Liber secretariorum aliame Minorise (1343-1353), fs. 19v$20 \mathrm{v}$

IIII $^{\mathrm{o}}$ nonas junii.

Bellsom ${ }^{1}$ Escapat, judeus, cum testimonio huius publici instrumenti promito et convenio bona fide ac firma et valida stipulatione vobis, Barono Jucefi, judeo Minorise secretarioque aliame judeorum Minorise, quod ${ }^{2}$ 
a primo venturo festo sancti Johannis Babtiste usque ad quinque annos primo continue venturos et completos contribuam et exsolvam /f. 19v/ certam partem pro questiis, prestitis ${ }^{3}$, talliis et aliis quibuscumque exactionibus regalibus et in tributis et aliis sumptibus et missionibus regalibus et vicinalibus ${ }^{4}$ et quibuscumque aliis dicte aliame et ipsam aliamam solvere contingentem per dictum tempus quinque annorum quocumquemodo et quacumque ratione seu causa, in quibus contribure promito per dictum tempus in hunc modum inferius declaratum dum taxat et non alter. $\mathrm{Nam}^{5}$ per duos annos primos dictorum quinque annorum solvam et solvere promito vobis vel successoribus vestris in dicto officio quadragintam solidos videlicet anno utroque ipsorum duorum priorum ${ }^{6}$ annorum, viginti soli$\operatorname{dos}^{7}$ scilicet, in primo venturo ${ }^{8}$ festo Natalis Domini, decem solidos, et in festo ${ }^{9}$ sancti Johannis Babtiste proximo tunc ${ }^{10}$ sequenti, alios decem solidos, et postea secundo anno dictorum priorum duorum annorum in dictis terminis vobis faciam similes solutiones. In residuis autem tribus annis et ultimis dictorum quinque annorum solvam vobis nonaginta solidos videlicet, anno quolibet dictorum trium annorum, triginta solidos, de quibus solvam anno quolibet ipsorum trium annorum in festo Natalis Domini ${ }^{11}$, quindecim solidos, et in festo sancti Johannis Babtiste, alios XV solidos, quas quidem solutiones faciam vobis et facere promito in dictis terminis ut premititur diebus adiatis, denarios sine pignore et sine aliqua dilatione et cetera. Et insuper promito vobis quod in casu tamen quo ego meum domicilium teneam seu foveam infra dictum tempus in dicta civitate prout domicilium est foveri et teneri assuetum, dabo et solvam vobis ultra predicta per dictum tempus, quinquaginta solidos pro parte mea sumptum et missionum quarumcumque dicte aliame pro ipsam aliamam qualitercumque fiendarum per dictum tempus, de quibus quinquaginta solidos solvam vobis in utroque dictorum terminorum et festivitatum anno quolibet dicti temporis, quinque solidos. Ita tamen quod ad alia exsolvenda in predictis vel aliis ${ }^{12}$ pro dictam aliama vel occasione eiusdem seu negotiorum ipsius per dictum tempus quinque anorum minime tenear ullomodo immo cum quantitatibus supradictis sim cum bonis meis quitius et immunis ab omnibus et singulis questiis, prestitis et aliis exactionibus regalibus supradictis et ab omnibus sumptibus et missionibus dicte aliame queque per totum dictum tempus per dictam aliamam solvi debeant quoquomodo. Nec vos me vel bona mea possitis obligari facere in debitis vel aliis negotiis dicte aliame $\operatorname{sed}^{13}$ me et bona mea teneamini servare quitium et immunem ab 
omnibus et singulis supradictis, me tamen solvente dictas peccunie quantitates in dictis terminis et ut superius continetur. Pro predictis vero et cetera; obligo et cetera; renuntio et cetera. Fideiussor Bonjucha ${ }^{14}$ Astruch, judeus Minorise, qui mecum et cetera. Ego igitur fideiussor et cetera; suscipiens et cetera; promito et cetera; sub obligatione et cetera. Renuntio et cetera. Ad hec ego, Baronus ${ }^{15}$ Jucefi, judeus secretaris predictus, consentiens predictis ut superius continetur, promito et convenio bona fide ac firma et legali stipulatione vobis, dicto ${ }^{16}$ Belsom Escapat, judeo, quod vobis solvente dictas peccunie quantitates in dictis terminis et per modum predictum ego et successores mei in dicto officio servabimus vos et bona vestra penitus sine dampno ab omnibus questiis, talliis et exactionibus ac sumptibus et missionibus supradictis, defendendo vos cum privilegiis ${ }^{17}$ et aliis immunitatibus dicte aliame ubi vobis necessario fuerit sicut aliquem alium singularem dicte aliame ${ }^{18}$ per dictum tempus. Attamen si per dicta aliama vel pro negotiis eiusdem ubicumque aliquod sustinueritis dampnum vel aliquas /f. 20v/ feceritis missiones, dum ${ }^{19}$ tamen in dicta civitate Minorise vestrum domicilium foveatis, totum id quicquid sit et quantum fuerit, promito vobis et vestris incontinenti cum inde fuero requisitus reddere et cetera. Vobis tamen vestrum domicilium in dicta civitate fovente aliter ${ }^{20}$, hoc est in casu quo non teneretis vestrum domicilium in civitate eadem, non teneamur ego vel mei successores in officio predicto seu dicta aliama ad restituendum vobis dampna et missiones predictas per vos faciendas et sustinendas, nisi hoc fieret et per vos sustineretur ob culpam et negligentiam dicte aliame seu propter pignora vobis fienda mora seu dilatione questiarum ${ }^{21}$ vel aliarum exactionum regalium ${ }^{22}$ per dictam aliamam solvendarum que per eandem aliamam exsolvi cessarentur seu plus debito prolongerentur ${ }^{23}$. Dictis vero missionibus et dampnis in casu quo restituende essent secundum modum predictum, credatur sacramento per vos prestando super predictis ad judicium tunc secretarii vel secretariorum dicte aliame. Obligo bona dicte aliame et cetera; renuntio et cetera. $\operatorname{Vos}^{24}$ vero transactis dictis quinque annis, postquam tamen per vos cum effectu satisfactum fuerit in quantitatibus peccunie supradictis, possitis cum bonis vestris alibi vestrum domicilium transferre ${ }^{25}$ et tenere et ubi vobis placuerit contribuere extra dictam civitatem sine aliquo obstaculo et impedimento mei vel alterius cuiuscumque. Testes Petrus Segarra et Petrus Ferrarii, faber de civitate Minorise ${ }^{26}$. 
1. Dues ratlles obliqües al damunt en senyal de ferma. 2. Segueix a die presenti quo presens conficitur instrumentum, ratllat; a primo venturo festo sancti Johannis Babtiste, interlineat. 3. Segueix et alii et, ratllat; talliis, interlineat. 4. Segueix dicte a <liame $>$, ratllat. 5. Nam, interlineat. 6. priorum, interlineat. 7. Segueix videlicet, ratllat. 8. Segueix fests, ratllat. 9. Segueix Ascensionis Domini, ratllat; sancti Johannis Babtiste, interlineat. 10. tunc, interlineat. 11. Segueix trigin<ta $>$, ratllat. 12. in predictis vel aliis, interlineat. 13. Segueix inde, ratllat. 14. Dues ratlles obliqües al damunt en senyal de ferma. 15. Dues ratlles obliqües al damunt en senyal de ferma. 16. dicto, interlineat. 17. Segueix dicte, ratllat. 18. Segueix attamen, ratllat. 19. dum, interlineat. 20. Segueix in, ratllat. 21. Segueix predictam aliamam, ratllat. 22. Segueix que, ratllat. 23. Segueix in casu tamen, ratllat. 24. Segueix insuper, ratllat. 25. transferre, interlineat. 26. Afegit a continuació, Sint duo de quibus unum uterque tradatur. Al marge esquerre f. 19v, XII denarios, Bellsom.

Recibido: $26 / 04 / 2016$

Aceptado: 08/10/2016 